IDOIA MURGA CASTRO

UNIVERSIDAD COMPLUTENSE DE MADRID

\title{
Maruja Bardasano: entre la danza y la pintura en el exilio mexicano
}

$\mathrm{M}$ aría Francisca Bardasano Rubio, conocida como Maruja Bardasano (fig. I), nació en Madrid en 1935 en el seno de una familia de artistas; hija de José Bardasano Baos y Juana Francisca Rubio, dos de los pintores más comprometidos por aquel entonces con las medidas que impulsaba la Segunda República Española. El golpe de Estado que dio inicio a la guerra civil, apenas un año después del nacimiento de Maruja, obligó a la familia a emprender el camino del exilio hasta llegar a México. Allí comenzó una nueva etapa de casi veinte años, durante la cual la artista se formó tanto en pintura como en danza clásica para convertirse en una de las jóvenes españolas refugiadas en México más brillantes y polifacéticas. Formó parte de compañías como el Ballet Concierto y el Ballet de Nelsy Dambre, con quienes interpretó grandes piezas del repertorio clásico y nuevas coreografías de Sergio Unger, Felipe Segura, Carletto Tibón, César Bordes y Michel Panaieff. Compartió escenario con bailarines como Lupe Serrano, Laura Urdapilleta, Tomás Seixas, Socorro Bastida, Jorge Cano, Déborah Velázquez y Francisco Arainza, entre otros, y llegó a ser nombrada primera solista. Paralelamente, comenzó su práctica de la pintura, una faceta que desarrolló con más fuerza a partir de su retorno a Espańa en 1956 y de su posterior abandono de la danza. En este artículo se retoman sus aportaciones más relevantes en ambas disciplinas artísticas, con especial énfasis en su faceta de bailarina.

Al ser la danza un arte efímero, resulta imposible volver a contemplar los espectáculos en los que actuó la madrileña, de los que además hasta la fecha no se han localizado filmaciones. Por ello, para llevar a cabo este estudio, ha sido 
necesario recurrir a todo tipo de fuentes secundarias, gráficas y escritas, desde fotografías hasta programas de mano, hemerografía, bibliografía de la época y, sobre todo, a la memoria de la propia artista quien, en varias entrevistas que le hice, ha recreado los años de su juventud en México. ${ }^{I}$ La recuperación de su obra ayuda a completar la brillante historia de la danza mexicana de mediados del siglo xx y a descubrir las aportaciones de una interesante figura del exilio republicano en México 76 años después del fin de la guerra civil española.

\section{Los Bardasano-Rubio, una comprometida familia de artistas}

La vida y la obra de Maruja Bardasano han estado particularmente condicionadas por la importante figura de sus padres (fig. 2), cuya comprometida trayectoria profesional en la Espańa de las décadas de 1920 y 1930 y en el núcleo de españoles refugiados en México es necesario sintetizar en las siguientes líneas. ${ }^{2}$ José Bardasano Baos (Madrid, I9IO-I979) fue uno de los pintores y cartelistas más conocidos del panorama anterior a la guerra civil. Desde 1922 se formó en la Escuela de Artes y Oficios y, para finales de esa década, había publicado sus primeras ilustraciones en el diario El Socialista y había sido nombrado director artístico de la Agencia Rex. En 1934 protagonizó su primera exposición en la Sociedad de Amigos del Arte madrileña. Ese mismo año obtuvo la segunda medalla de la Exposición Nacional gracias a un bello retrato de Juana Francisca Rubio, quien se había convertido en su mujer. En 1935 obtuvo una beca del Legado del Conde de Cartagena para estudiar pintura en Bélgica, Holanda y Francia — donde entabló amistades cruciales que le ayudarían a embarcarse a México una vez que la familia salió de España en los últimos momentos de la guerra. A su regreso, en abril de 1936, expuso su obra en el Círculo de Bellas Artes de Madrid, junto con Godofredo Ortega y Muñoz y Juan Manuel.

Su aportación clave al inicio del conflicto bélico fue la fundación del taller La Gallofa, sito primero en la Gran Vía — en los antiguos talleres de la editorial

I. Agradezco enormemente a Maruja Bardasano, a Carlos Peña, su marido, y a su hija Rosalva su amable ayuda y su constante disponibilidad para llevar a cabo esta investigación.

2. Véase José Luis Bardasano Rubio, "La obra de la familia Bardasano en el exilio de México", en Analogías en el arte, la literatura y el pensamiento del exilio español de I939, eds. Miguel Cabańas Bravo, Dolores Fernández Martínez et al. (Madrid: Consejo Superior de Investigaciones Científicas, 2010), I55-I6I. 


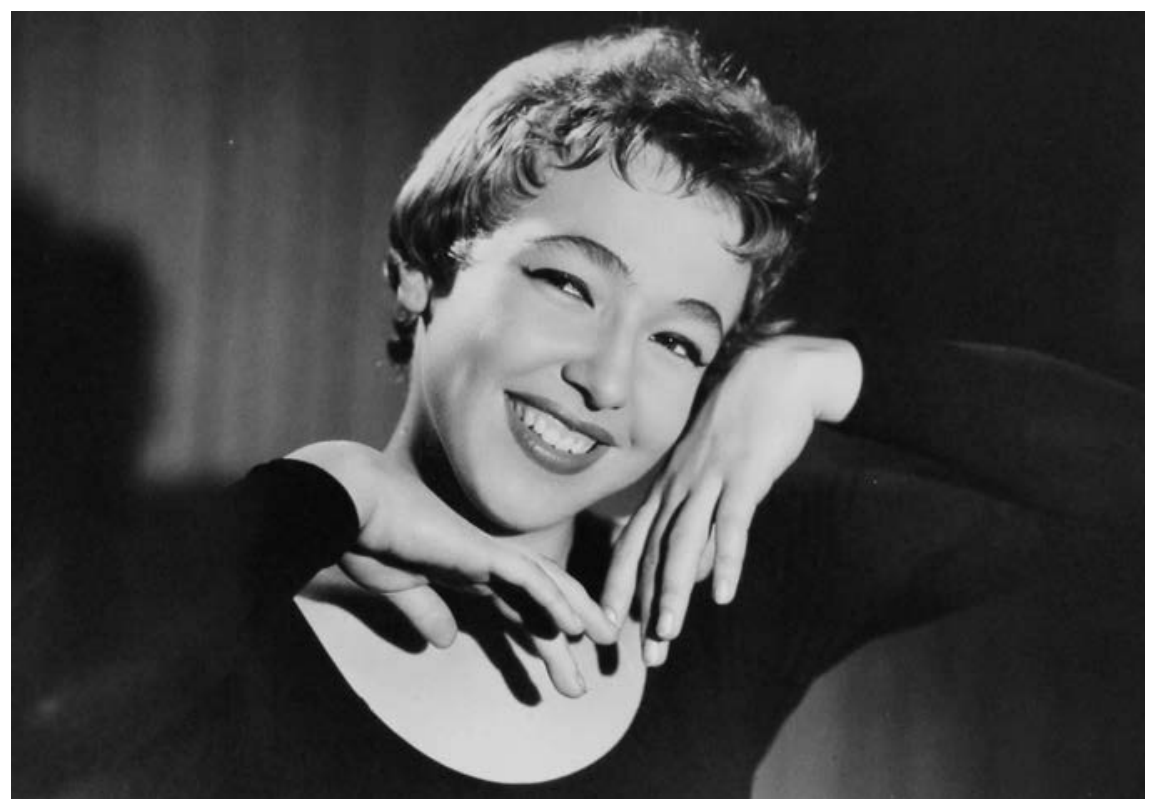

I. Maruja Bardasano. Colección Maruja Bardasano.

Rivadeneyra, entonces el número 8 de Conde de Peñalver-y, más tarde, en el Palacio March, una organización que dependía de las Juventudes Socialistas Unificadas (Jsu). De aquellos años cabe mencionar los carteles titulados Exposición Nacional de la Juventud, El libro, el mejor amigo del convaleciente, España y Catalans! Val més morir dempeus que viure agenollats! (Archivos Estatales, Ministerio de Educación, Cultura y Deporte, MECD). En este taller también trabajó Juana Francisca Rubio (Madrid, I9II-2008), puntera dibujante, ilustradora y pintora, que por entonces estaba vinculada a la Unión de Muchachas, perteneciente a las Jsu. ${ }^{3}$ Entre sus actividades de aquellos años, cabe destacar la muestra individual que protagonizó en el Lyceum Club madrileño en febrero de $1935 .{ }^{4} \mathrm{Su}$ apoyo a los nuevos reclamos de la mujer y su compromiso político — propio de la generación que compartía con otras destacadas artistas, como Manuela Ballester, Elvira Gascón, Remedios Varo, Elisa Piqueras o

3. Lila Pérez Gil, "Paquita Rubio, cartelista durante la Guerra Civil", El País, 30 de enero de 2008, http://elpais.com/diario/2008/or/30/necrologicas/r20164760I_850215.html.

4. Don Lápiz, "Croquis", El Siglo Futuro, 4 de febrero, 1935, 3. 
Carmen Millá— 5 continuó más tarde, al afiliarse a la Unión de Mujeres Antifascistas. Entre sus obras, se conservan carteles como: Campamento de Unión de Muchachas, Conferencia de las muchachas de Madrid, „Compañeras! Ocupad los puestos de los que se van a empuñar un fusil y Nuestros brazos serán los vuestros (Archivos Estatales, MECD). En una entrevista que le hicieron en 2004, a propósito de una exposición de algunos de sus carteles, la artista apuntó: "Ninguno de los dos éramos cartelistas [...] pero en aquel momento pusimos nuestro arte al servicio de una causa que nos parecía justa". 6 A comienzos del otoño de 1936 Bardasano obtuvo el premio del concurso Homenaje a las Milicias, convocado por la junta directiva del Frente Popular de la Cámara Oficial del Libro de Madrid?

Era evidente que tanto Bardasano como Juana Francisca habían optado por la línea del realismo como la estética adecuada para su pintura. No en vano, en esos años el compromiso político de los artistas estuvo muy condicionado por los dictados de influencia soviética del realismo socialista, marcados especialmente a partir del Congreso de Escritores Soviéticos de 1934 y que, en su exportación al medio artístico español, generó avivados debates entre los defensores de ese lenguaje directo, comprensible y eficaz para trasladar un mensaje ideológico determinado, frente a los partidarios de las vanguardias. ${ }^{8}$

5. Véanse Pilar Muñoz López, "Mirada de género en la creación plástica de artistas españolas”, en Feminismos e interculturalidad. V Congreso Internacional de la Asociación Universitaria de Estudios de las Mujeres, eds. Mercedes Arriaga, Ángeles Cruzado et al. (Madrid: Asociación Universitaria de Estudios de las Mujeres, 2008), 30I-322; y Ana Boned, "Creativas en el exilio mexicano. Apuntes biográficos y artísticos de Elvira Gascón, Remedios Varo y Manuela Ballester", Creatividad y Sociedad, núm. Is (noviembre, 20IO): I-22. Se puede encontrar una entrevista a Juana Francisca Rubio integrada en el documental de Jorge Montes, Mujeres en la República, Universidad Nacional de Educación a Distancia, 20I2, https:/canal.uned.es/ $\mathrm{mmobj} / \mathrm{index} / \mathrm{id} / 7843$, consultado el 27 de septiembre, 2014.

6. Ritama Muñoz-Rojas, "Un puñetazo en un ojo", El Pais, 30 de enero de 2004, http://elpais.com/diario/2004/oI/30/madrid/I075465477_850214.html; Carteles de la guerra I936-1939: Colección de la Fundación Pablo Iglesias, catálogo de la exposición (Madrid: AEci/Fundación Pablo Iglesias/Lunwerg, 2005).

7. "Fallo de un concurso", El Sol, 9 de octubre de 1936, 2.

8. En este sentido, resulta especialmente ilustrativa la polémica mediante el intercambio de cartas abiertas en las páginas de Nueva Cultura entre Alberto Sánchez — defensor de su Escuela de Vallecas - y Antonio Rodríguez Luna — partidario del realismo como estética más propia de los nuevos tiempos de compromiso político. Miguel Cabañas Bravo, Rodríguez Luna, el pintor del exilio republicano español (Madrid: Consejo Superior de Investigaciones Científicas, 2005), 53-56. 


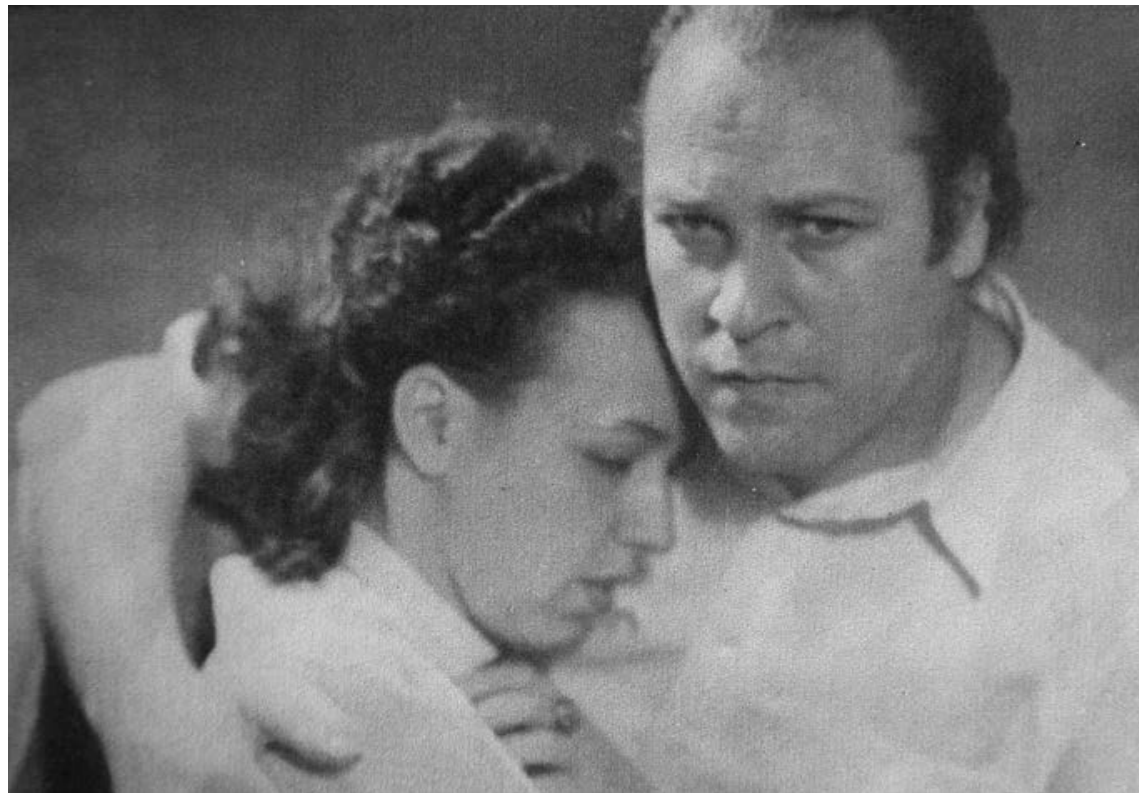

2. Juana Francisca Rubio y José Bardasano Baos. Colección Maruja Bardasano.

Con el avance de la guerra, La Gallofa se trasladó a Valencia, donde se instaló la familia Bardasano-Rubio. Allí, José se integró a la Subsecretaría de Propaganda del Ministerio de Estado y al Comisariado General de Guerra de Valencia. En ese tiempo, el artista realizó una serie de grabados que publicó en un libro en 1937 con el título de Mi patria sangra: estampas de la independencia de España y participó, al igual que Juana Francisca, en el célebre pabellón español de la Exposición Internacional de París. Asimismo, parte de la obra creada en el marco de La Gallofa se incluyó en la Gran Exposición de Juventud Española, que abrió en Valencia entre agosto y septiembre de 1937.9 Quedaba patente, por tanto, el compromiso del significado matrimonio en la defensa de la causa republicana.

9. "La Gran Exposición de la Juventud Espańola", El Sol, i7 de agosto de 1937, 2; "La Gran Exposición de la Juventud Española", La Libertad, I7 de agosto de 1937, 3. Véanse también La Hora [Diario de la Juventud, Jsu, Valencia], 7 de mayo de 1937; y ;Al Frente! [Boletín de la Juventud Socialista Unificada, Madrid], I2 de septiembre de 1937. Citados en Juan Manuel Fernández Soria, Juventud, ideología y educación (Universitat de València, 1992), I04. 
Tras la victoria franquista, ambos pintores cruzaron a Francia; Juana Francisca, con su hija de la mano, mientras que José fue confinado en el campo de concentración de Argelès-sur-Mer, en donde continuó realizando dibujos que documentaron las condiciones en las que vivieron los españoles. Gracias a los mencionados contactos establecidos años antes durante su estancia como becario, Juana Francisca y Maruja pudieron reunirse con José y ser parte de los pasajeros del Sinaia, llegando a México en 1939 (fig. 3). ${ }^{\text {IO }}$

Como artistas comprometidos que eran, ambos participaron en el diario de a bordo de aquel barco, en el que distintos creadores colaboraron publicando poemas, dibujos, ensayos y testimonios de aquellos i8 días de viaje que los separaban de su derrotada España, pero que les daban esperanzas por la nueva vida que podrían comenzar acogidos por México, gracias a la invitación oficial ofrecida por el presidente Lázaro Cárdenas a los republicanos. En sus páginas se daba cuenta de la exposición que ambos montaron a bordo junto a Aurelio Arteta, Ramón Gaya, Germán Horacio, Ramón Peinador, Francisco Camps Ribera, Ramón Tarragó, Julián Oliva, Eduardo Robles, Enrique Climent, José Agut, Carmona, Rebatte, Jordana y Acitores. ${ }^{\text {II }}$ Ahí, los artistas explicaban que sus trabajos provenían de los campos de concentración y de la misma vida a bordo, y denotaban "un espíritu creador que, en circunstancias penosas y precarias, ha sabido conservar su facultad estética, joven, y acusa una sana vinculación política a la causa del pueblo". ${ }^{\text {I2 }}$

Ya en tierras mexicanas, José Bardasano Baos, como pintor respetado, recibió varios encargos del gobierno y expuso su obra en numerosas ocasiones. ${ }^{13}$

Io. Véase el listado de pasajeros del Sinaia en la Fundación Pablo Iglesias. Las fichas del Servicio de Migración con su entrada a Veracruz (ref. 0632 y 0639) se pueden localizar en la Secretaría de Gobernación de México, Archivo General de la Nación de México y en línea, en el portal de Movimientos Migratorios Iberoamericanos dependiente del Portal de Archivos Españoles (pares), Ministerio de Educación, Cultura y Deporte: http://pares.mcu.es/MovimientosMigratorios, consultado el 27 de septiembre de 2014.

II. "Nuestra exposición", Sinaia, núm. 17, in de junio de 1939, 3, en Sinaia. Diario de la Primera Expedición de Republicanos Españoles a México, introd. de Fernando Serrano, presentación y epílogo de Adolfo Sánchez Vázquez (México: Universidad Nacional Autónoma de México/Universidad Autónoma Metropolitana/La Oca, Redacta, 1989).

I2. "Nuestra exposición", 3.

I3. Entre la actividad llevada a cabo por José Bardasano en el exilio, podemos citar aquélla ligada a la editorial, como la publicación del libro Primeros dibujos de Bardasano hechos en México, los que aparecerán en la quinta edición de "Las calles de México", de don Luis González Obregón (i6 láminas y portada) (México: Botas, 1939); Bardasano. Su obra, pról. Santiago 
3. José Bardasano Baos con su hija Maruja a bordo del Sinaia, I939. Colección Maruja Bardasano.

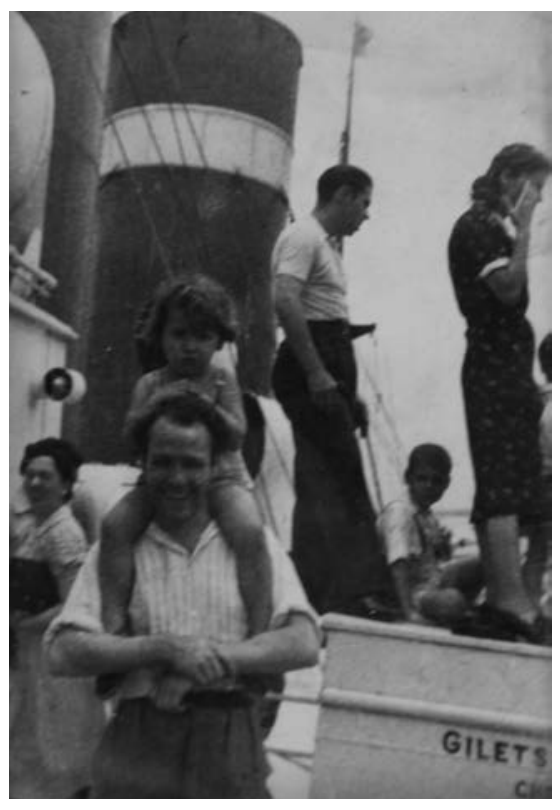

Como es bien conocido, México se había convertido en el foco de acogida de un mayor número de exiliados, entre quienes se contaron muchos intelectuales y creadores llegados principalmente en los barcos fletados entre 1939 y 1940 - aunque otros tantos arribaron en los años de la segunda guerra mundial. Los especialistas consideran al matrimonio madrileño como parte de la primera generación de artistas refugiados: aquellos que emigraron ya adultos y cuyas experiencias durante la guerra habían marcado su obra de manera más determinante que el influjo mexicano posterior. Por el contrario, el caso de su hija, Maruja, sería el de la segunda generación: los jóvenes españoles que se formaron y desarrollaron sus carreras en México, ya permeables a las experiencias en

Carrillo, secretario general de la Juventud Socialista Unificada de España (México: imprenta de M. León Sánchez, 1943) y la ilustración de El cantar de los cantares de fray Luis de León, Colección Eros (México: Leyenda, 1944). Presentó su obra en exposiciones individuales y colectivas, en espacios como la galería Arte y Decoración (1940-1942), el Salón de la Flor (I945), la Casa de Arte (1946-1947) y el Círculo de Bellas Artes (1946, I948-1949), entre otros. Justino Fernández, "Catálogo de exposiciones de arte en 1940”, “194I", “1942”, “1945” y “1947”, Anales del Instituto de Investigaciones Estéticas, suplementos (I94I-I943, I946, I948) 8-IO, I3, I5, citado en Cabańas Bravo, Rodríguez Luna, I56, 160, I64-165, 210, 216. 
el nuevo país, que integraron con su legado español. ${ }^{14}$ De hecho, como se verá a continuación, la defensa de la causa republicana y la presencia de temáticas y actitudes ligadas a las consecuencias de la guerra fueron mucho más fuertes en la trayectoria de los padres de Maruja que en los de la pequeña artista, cuya feliz infancia y juventud en tierras mexicanas parecieron ajenas al drama de la emigración forzada que hubo de sufrir toda la familia.

Una vez establecidos en México, José Bardasano combinó la práctica pictórica con su faceta docente, al abrir una frecuentada escuela de arte en su propia casa, primero, en la colonia Del Valle, después, en la calle Villahermosa de la colonia Cuauhtémoc y, finalmente, en la avenida de las Palmas — luego avenida Homero- número sio de la colonia Chapultepec-Morales. ${ }^{15}$ El peso de las clases recayó en José, mientras Juana Francisca apoyó su labor artística desde un segundo plano, dedicada a atender a su familia. Sin embargo, también trabajó como ilustradora para libros infantiles, literatura clásica y de texto de la Secretaría de Educación Pública (SEP), iluminó postales, especialmente en las épocas navideñas y fue diseñadora de la firma cosmética Sara Glein. Su segundo hijo, José Luis, nació en 1947, ya en la ciudad de México. ${ }^{16}$

La pintura del matrimonio continuó en la línea realista defendida en la España bélica, siguiendo los argumentos que se habían convertido en bandera del arte espańol en el exilio. Como ha señalado el investigador Miguel Cabańas Bravo, este lenguaje realista, dentro de su pluralidad de estilos, fue característico del arte de la emigración republicana. ${ }^{17} \mathrm{~A}$ las experiencias asumidas

I4. Miguel Cabañas Bravo, "De la alambrada a la mexicanidad. Andanza y cerco del arte español del exilio de 1939 en tierras aztecas", en Después de la alambrada. El arte español en el exilio. 1939-1960, dir. Jaime Brihuega, catálogo de la exposición (Madrid: Sociedad Estatal de Conmemoraciones Culturales/Universidad de Zaragoza, 2009), 59-60.

I5. Anteriormente había impartido clases gratuitas a obreros en la imprenta de Manuel León Sánchez (Bardasano Rubio, "La obra de la familia Bardasano", 156). Sobre su papel docente véase "La obra de los desterrados españoles en México. Pintura", Boletin de Información. Unión de Intelectuales Españoles, núm. 5 (junio-septiembre, 1957): 21.

16. En la actualidad, José Luis Bardasano es catedrático de la Facultad de Medicina de la Universidad de Alcalá de Henares.

17. En su estudio se señala que "estuvieron presentes desde el más puro realismo socialista de un José Renau, a otros muchos realismos, como el regionalismo de Arteta, la expresión del horror y lo popular de Germán Horacio, el ilustrado y reflexivo apego a la realidad de Miguel Prieto, el realismo sin preocupaciones vanguardistas de Bardasano, el paisajismo vacilante de Lizárraga o la luminosa sencillez de la pintura de Cristóbal Ruiz". Cabańas Bravo, Rodríguez Luna, I42. Véase también Jaime Brihuega, "Después de la alambrada. Memoria y metamorfosis en el arte del exilio español", en Brihuega, Después de la alambrada, 17-39. 
desde España se sumaba, además, el ambiente artístico del país de acogida, fuertemente marcado por el muralismo y el grabado. Con todo, en el caso de los Bardasano, su obra de temática más comprometida de los tiempos bélicos fue poco a poco suavizándose ya en la etapa mexicana, sin ceder por ello un ápice en su realismo ni en su postura política por la causa republicana. No en vano José Bardasano y Juana Francisca Rubio fueron dos de los firmantes de la Declaración de los pintores españoles republicanos residentes en México el $\mathrm{I} 3 \mathrm{de}$ octubre de 1951, contestación de los artistas exiliados que condenaban la convocatoria de la I Bienal Hispano-Americana, impulsada por el gobierno franquista por medio de su Instituto de Cultura Hispánica:

Los pintores españoles en el destierro vemos con profunda satisfacción la repulsa general que ha merecido esta fanfarronada imperial, al querer asociar a su régimen de terror y de traición la conciencia más pura del arte hispanoamericano, que comparte el amor a la libertad e independencia de sus pueblos.

Nosotros, los pintores republicanos españoles, condenamos enérgicamente esta farsa, con la que el régimen franquista pretende ganar un prestigio que ha perdido, dentro y fuera de España. ${ }^{\mathrm{I}}$

Tal declaración conllevó la organización de la I Exposición Conjunta de Artistas Plásticos Mexicanos y Españoles Residentes en México, también conocida como la Contra-Bienal, que se organizó en el Pabellón de la Flor del Bosque de Chapultepec en febrero de I952, donde participó el matrimonio de pintores — con obras tituladas Teruely, curiosamente, Bailarinas. ${ }^{19} \mathrm{Al}$ tomar partido en una de las acciones más importantes contra el franquismo, organizado entre los exiliados, la familia Bardasano-Rubio demostró su lealtad a la lucha por la democracia en España. Estas posturas políticas y elecciones plásticas, como se verá más adelante, fueron determinantes para entender la futura producción de Maruja. Con su nueva vida encauzada y un ambiente artístico tan propicio, el contexto era el idóneo para que la pequeña artista desarrollara todo su potencial creativo en los ańos siguientes.

18. "Declaración de los pintores españoles republicanos residentes en México", Nuestro Tiempo, I de noviembre de I95I. Reproducido en Cabańas Bravo, Rodríguez Luna, 242.

19. Véase la detallada investigación sobre la Bienal Hispano-Americana en Miguel Cabanás Bravo, La politica artística del franquismo (Madrid: Consejo Superior de Investigaciones Científicas, 1996), 532, 536-537. 


\section{Maruja Bardasano y la danza mexicana}

Con tales ascendientes familiares, era lógico que Maruja Bardasano, llegada a México siendo una nińa, aprendiese a dibujar y a pintar simplemente estando en su casa y observando a sus padres. No obstante, muy pronto descubrió otra de sus grandes pasiones, la danza, tal y como ella señaló años más tarde en una entrevista: "No sé cuándo nació en mí el deseo de ser bailarina, pero creo que esto ha sido siempre una idea fija en mi mente. En el colegio siempre bailé en las fiestas". ${ }^{20}$ En otra ocasión recordó: "Gustándome todas las manifestaciones escénicas, cuando pude asistir con mis padres a un concierto de ballet —andaría por los doce años_, lo que vi se convirtió en obsesión. Ya no dejaba vivir tranquilo a nadie en mi casa". ${ }^{21}$

De esta forma, compaginó sus lecciones artísticas con los cursos del Colegio Windsor, donde terminó la Enseñanza Primaria en 1947.22 Poco después, sus padres le permitieron apuntarse a clases de baile, actividad realizada simultáneamente con estudios de periodismo e historia del arte. Así, comenzó su formación con la maestra Beatriz Blanco, conocida como Miss Trixy, en clásico, danza espańola, claqué y piano, que luego amplió con las lecciones de la profesora Nina Shestakova. Esta última, de procedencia moscovita, había estudiado ballet en la Escuela Imperial y desde 1930 ofrecía lecciones en su academia, por la que pasaron futuras personas famosas de la danza mexicana.

Como se ve, el aprendizaje de Bardasano se dirigió fundamentalmente a la disciplina clásica, algo poco común en otros bailarines del exilio español en distintos puntos del mapa, puesto que tanto el sentimiento de nostalgia de la cultura de la tierra perdida como la pura demanda del público que buscaba aquella imagen estereotipada de "lo español" llevaban a que los artistas se especializaran en otro tipo de repertorio. En este sentido, la aportación más destacada y temprana del fenómeno del exilio español en México, tras la victoria del general Franco, había sido la colaboración en la fundación del primer grupo de danza mexicana moderna, La Paloma Azul, a principios de 1940. Diri-

20. Archivo Maruja Bardasano (en adelante, Амв), Bambi, "Historia que comienza mañana. La de Marouka Bardasano", recorte de prensa. Ana Cecilia Trevińo, Bambi, fue una periodista y pintora que frecuentó las clases de pintura de José Bardasano. Maruja recuerda que recibió su apodo en aquellos años, pues sus grandes ojos recordaban a los del cervatillo de la película de Disney.

21. AMB, Antonio de la Villa, "María Bardasano y su arte", [1956] recorte de prensa.

22. Амв, Certificado de Enseñanza Primaria, SeP, 28 de noviembre de 1947. 
gido por la coreógrafa estadounidense Anna Sokolow y el literato y el músico españoles José Bergamín y Rodolfo Halffter, en su seno se estrenaron piezas ligadas a las circunstancias del exilio — como Don Lindo de Almería, Balcón de España, Enterrar y callar o Lluvia de toros-, a la creación mexicana - como El renacuajo paseador y Entre sombras anda el fuego - y la danza moderna estadounidense - como Matanza de los inocentes y Baladas en estilo popular. ${ }^{23}$ En todos estos casos, las coreografías prescindieron del vocabulario clásico para recurrir a la danza moderna y española.

También en el marco de este fenómeno de la emigración forzada podemos citar varias bailarinas refugiadas en México que cultivaron la disciplina española: Emilia Díaz — conocida profesora por cuya escuela pasaron muchos artistas_-, Concepción Balcells — conocida como Isa Reyes_- Ana Guix Carreras —de nombre artístico Perla Gris_- las hermanas Guadalupe y Eugenia Ramallo Garci-Nuño o las hermanas Rodríguez — Gloria, Alicia y Azucena Rodríguez Fernández, hijas del famoso músico Marcial Rodríguez. Asimismo, aunque no se establecieron permanentemente en México, grandes personajes que vivieron el exilio desde los años bélicos, como Encarnación López, La Argentinita, Pilar López, Antonio Triana y Ana María Fernández, por citar algunas de las más notables, realizaron giras por el país con programas basados en piezas españolas. Lo habitual en estos bailarines establecidos en América era destacar por el flamenco, el folclor ibérico, la escuela bolera o la danza española estilizada. Sólo en el foco de acogida de españoles en la Unión Soviética es posible encontrar aportaciones como las de Violeta González García o Gerardo Viana — conocido también como Vladimiro Viana-, donde una fuerte tradición de la escuela rusa de ballet condicionó la formación y la contratación de artistas en compañías clásicas. Por ello, la concentración de Maruja Bardasano en el ballet clásico la convierte prácticamente en una excepción en la nómina de artistas del exilio republicano establecidos en México. Quizá su juventud, unida a que frecuentó círculos más mexicanos que españoles, la llevaron a centrarse en el ballet, dejando las disciplinas españolas de lado:

23. Para profundizar más sobre La Paloma Azul, véanse: Idoia Murga Castro, "Encuentros en escena: danza mexicana y exilio republicano", en Modernidad y vanguardia: rutas de intercambio entre España y Latinoamérica (1920-1970), coords. Paula Barreiro López y Fabiola Martínez Rodríguez (Madrid: Museo Nacional Centro de Arte Reina Sofía, 2015), 49-58; Idoia Murga Castro, "Republicanos españoles en la escena mexicana: música, danza y artes plásticas en el exilio", Huellas y rostros. Exilios y migraciones en la memoria musical de Latinoamérica (México: Universidad Nacional Autónoma de México), en prensa. 
He leído más que he visto del baile español, en esa modalidad esencialmente andaluza. Baile de inspiración, en que juegan la guitarra, las castańuelas, el cante y el acompañamiento de palmas. Tiene desde luego mucho color, mucho brío - contemple usted a Carmen Amaya, a la Argentinita, que yo pude alcanzar a su paso por México, al propio "Chavalillo"- y sus realizaciones son siempre anárquicas, aun cuando no dejan de ser artísticas.

Como espectáculo, es algo definitivo, mucho más en esa época leída por mí, de una Antonia Mercé, nacida en el ballet y por tanto académica, al lado de su padre director de ballets, que descubrió el son armónico y dulce del castañoleo, e incorporó a Falla, Albéniz, Granados y Jiménez, al embrujo de sus bailes. Pero no olvide usted que sus realizaciones respondían a una base académica. ${ }^{24}$

Más adelante continuó su aprendizaje con Nelsy Dambre, nombre artístico de Marguerite Constance Coussignot de André, una bailarina instalada en México desde 1937, cuando arribó como integrante del Ballet Parisien. La fama de su ascendencia francesa le permitió participar en la formación de futuras grandes figuras de la danza mexicana, como Lupe Serrano - que desarrolló una importante carrera en compañías estadounidenses-, Gloria Contreras, la refugiada espańola Mercedes Pascual y la misma Maruja Bardasano. Dambre acabó fundando su propia compañía, que presentó distintas programaciones del Palacio de Bellas Artes en la ciudad de México a partir de 1949. ${ }^{25}$ En su agrupación trabajó puntualmente Sergio Unger, gran maestro y coreógrafo de una buena parte de las piezas representadas — a quien José Bardasano Baos retrató brillantemente (fig. 4)—, quien contaba por entonces con su propio grupo de alumnos, germen de su futura compañía. ${ }^{26}$ En aquellos ańos, a Maruja comenzaron a conocerla como Marouka, un guińo a la escuela rusa de ballet clásico que a ella nunca llegó a gustarle: "Como he ingresado a la carrera de la danza, adopté el [nombre] de Marouka (que tiene algo de francés y algo de ruso y mucho de bailarina) Bardasano". ${ }^{27}$

24. Амв, De la Villa, "María Bardasano y su arte".

25. Patricia Aulestia, Despertar de la república dancística mexicana (México: Ríos de Tinta, 20I2), 427-428.

26. Felipe Segura, Nelsy Dambre. Un ballet para México (México: Instituto Nacional de Bellas Artes/Centro Nacional de Investigación, Documentación e Información de la Danza José Limón, 1998), IOI.

27. Амв, Bambi, "Historia que comienza mañana". 
4. José Bardasano Baos, Retrato de Sergio Unger. Colección particular.

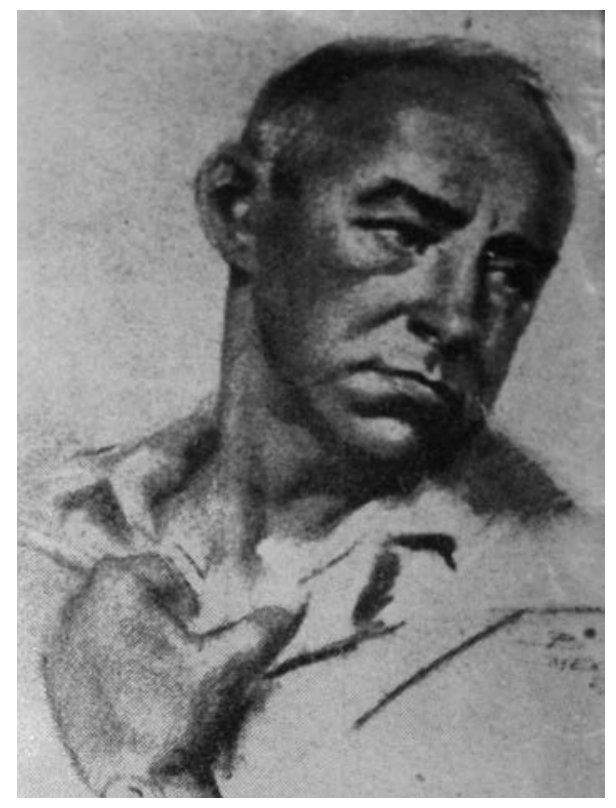

Para finales de la década de 1940, el panorama de la danza mexicana había experimentado grandes avances con la fundación de escuelas y compañías nacionales que impulsaban fundamentalmente la disciplina moderna en el marco de la mexicanidad del movimiento nacionalista. ${ }^{28}$ En 1932 la fundación de la Escuela Nacional de Danza —en la que impartían clase, entre otros, Gloria y Nellie Campobello_-, dependiente del Departamento de Bellas Artes de la SEP, ofrecía ya formación en bailes mexicanos junto a la técnica clásica académica, una línea que continuaron ambas maestras en el Ballet de la Ciudad de México (1943). En 1947 se fundó la Academia de la Danza Mexicana, proveniente de proyectos anteriores que habían buscado dotar de estructu-

28. Para profundizar en la historia de la danza mexicana del siglo xx, véanse: Alberto Dallal, La danza moderna (México: Fondo de Cultura Económica, 1975), y del mismo autor, "Lo nacional como proyecto y realización en la danza mexicana de hoy", Anales del Instituto de Investigaciones Estéticas XIII, núm. 52 (1983): 187-229; Margarita Tortajada Quiroz, Mujeres de danza combativa (México: Ríos y Raíces, 1998); Margarita Tortajada Quiroz, Danza y poder I. Proceso de formación y consolidación del campo dancístico mexicano (I920-1963) (México: Biblioteca Digital/Consejo Nacional para la Cultura y las Artes-Instituto Nacional de Bellas Artes-Centro Nacional de las Artes, 2008). 
ras adecuadas al aprendizaje y la conservación de un "estilo nacional dancístico". Bajo la dirección de Guillermina Bravo y Ana Mérida, se convirtió en toda una institución en la que se desarrollaron las enseñanzas de agrupaciones pioneras efímeras del principio de la década — como las de Anna Sokolow y Waldeen von Falkestein. ${ }^{29}$ El año siguiente Bravo conformó el Ballet Nacional de México, una compañía que sobrevivió hasta 2006 y acuñó un estilo renovador propio. En los ańos en los que Maruja Bardasano desarrolló su carrera de bailarina, la danza mexicana se consolidó como una de las más activas y renovadoras del panorama internacional, alumbró numerosas compañías y conformó lo que los investigadores han distinguido como el primer periodo de danza moderna, comprendido entre las décadas de los años cuarenta y cincuenta. $^{30}$ Entre 1950 y 1953 el Departamento de Danza del Instituto Nacional de Bellas Artes tenía como director a Miguel Covarrubias, quien impulsó la danza moderna nacionalista. Las distintas tendencias continuaron diversificándose en la década de 1950, y permitieron la fundación de nuevos grupos, como el Ballet de la Universidad — a las órdenes de Magda Montoya- (I95I), el Ballet Bonampak (1952) y el Ballet Mexicano (1955) — ambos dirigidos por Ana Mérida_, el Nuevo Teatro de Danza (1953), el Ballet Quinteto (1954) y el Ballet Contemporáneo (1954).

En el campo del ballet clásico, pequeñas agrupaciones particulares, dedicadas a la disciplina académica, vinieron a llenar el hueco que las grandes, con soporte público, no llegaban a cubrir por estar centradas en el desarrollo de la danza moderna mexicana. En ello tuvieron mucho que ver los bailarines extranjeros llegados en giras o establecidos en México a partir de la década de los años veinte del siglo xx, desde Hipólito Zybin hasta Karol Adamchevsky, pasando por Grisha Nabivach, Linda Costa y Xenia Zarina, entre otros, sin olvidar a tres maestros de Maruja Bardasano: Nina Shestakova, Nelsy Dambre y Sergio Unger. ${ }^{3 \mathrm{I}}$ El propio Felipe Segura, uno de los bailarines más destacados de la danza mexicana del siglo xx y futuro compañero y coreógrafo de Maruja, como veremos a continuación, recogió el papel que maestros como Dambre y Unger tuvieron en ese particular contexto dancístico en el que la madrileña desarrolló su carrera, al contribuir en gran medida a que el país

29. Antonio Luna Arroyo, Ana Mérida en la historia de la danza mexicana moderna (México: Publicaciones de Danza Moderna, 1959).

30. Alberto Dallal, La danza en México. Primera parte: panorama crítico (México: Universidad Nacional Autónoma de México-Instituto de Investigaciones Estéticas, 1995), I49, I55. 3I. Segura, Nelsy Dambre, II. 
contara con los cimientos de la formación en ballet clásico y diera a luz las primeras compańías clásicas:

Los grupos de Nelsy Dambre y Sergio Unger dependieron en todos los aspectos de estos destacados bailarines y maestros extranjeros, artística y económicamente. Supieron infundir a los bailarines mexicanos una conciencia profesional, los condujeron a una carrera, perdurable a la mayoría de ellos.

Sergio Unger y Nelsy Dambre tuvieron un desarrollo dancístico desde su niñez, la fortuna de que en sus países hubiera escuelas de gran tradición y categoría que los entrenó como profesionales y listos para emprender una carrera en cualquier lugar del mundo. Para México fue magnífico que vinieran, ellos trataron de que cada alumno tuviera el desarrollo técnico y artístico necesario. Las circunstancias eran muy diferentes, no había una selección, los muchachos hacían su escolaridad en otros lugares, los varones no contaban con la aprobación familiar y, desde luego, tampoco con su apoyo. Sergio Unger y Nelsy Dambre sintieron la necesidad de tener una escuela, impartir clases a todo tipo de alumnos, con talento y sin él, con el físico adecuado o sin él. Tuvieron, además, que encargarse de todo: clases y ensayos, hacer las coreografías, pagar el vestuario, iluminar, adaptar escenografías y hacer todos los arreglos administrativos y publicitarios. Y a pesar de la aceptación que tenía su trabajo para el público, que llenaba los teatros (siempre con pérdidas), de tener magníficas crónicas en los periódicos y revistas, nunca obtuvieron ayuda del gobierno o de instituciones particulares. Esto hace que su trabajo tenga un mayor realce. ${ }^{32}$

Según quedó documentado, Maruja Bardasano pisó el escenario por primera vez el 3 de diciembre de 1950 en una representación que la Escuela de Baile Clásico Nina Shestakova organizó en el Palacio de Bellas Artes, con la Orquesta Sinfónica del Instituto Nacional de Bellas Artes (INBA), dirigida por José Pablo Moncayo. El programa integró la pieza de Mikhail Fokine, Las silfides, el homenaje a una de las primeras obras del ballet romántico que utilizaba distintas partituras de Frédéric Chopin, así como Nochebuena, Nocturno — con música de Hubert de Blanck_ y Fiesta rusa — con partituras de Piotr Ilich Chaikovski y Modesto Mussorgski. ${ }^{33}$ Fue el comienzo de una significa-

32. Segura, Nelsy Dambre, I2-I3.

33. Амв, programa de mano, Ballet de Nina Shestakova, Palacio de Bellas Artes, México, I3 de diciembre, I950. Véase también Margarita Tortajada Quiroz, 75 años de danza en el Palacio de Bellas Artes (México: Instituto Nacional de Bellas Artes, 20IO), I23. 
tiva carrera como bailarina a lo largo de los siguientes seis años, con constantes estrenos en el seno de distintas compañías, que se detallan a continuación.

A finales de 1950, Maruja Bardasano aparecía como miembro del cuerpo de baile del Ballet de Nelsy Dambre, quien presentó en el escenario de Bellas Artes varios divertissements de los grandes éxitos de Chaikovski: El lago de los cisnes, La Bella Durmiente y El Cascanueces. El mencionado repertorio se programó durante la gira que realizó la agrupación en Xalapa, Veracruz, en el Teatro Lerdo de la ciudad. ${ }^{4}$ Para esta representación contaron con la participación de la Orquesta Sinfónica de Xalapa, dirigida por José Yves Limantour. Maruja figuró como solista en El lago e interpretó un pas de deux con Antonio Avilez en La Marcha de la princesa Aurora, una adaptación de La Bella Durmiente. Se trataba de puestas en escena muy austeras, pues la compañía todavía no había alcanzado la suficiente reputación y los contactos como para conseguir apoyos económicos que permitiesen montar estos ballets de la segunda mitad del siglo XIX con su correspondiente escenografía. Los bailarines — como explicaba Felipe Segura anteriormente y destacaba la prensa- ${ }^{35}$ debían confeccionarse su propio vestuario y no obtenían ninguna remuneración económica por actuar, aunque en gran parte de los programas de la coreógrafa francesa se indica que el diseño de vestuario dependía de Ana Junquera, responsable de la sastrería y utilería del teatro de Bellas Artes.

En febrero de 195I el Ballet de Nelsy Dambre volvió a actuar en el Palacio de Bellas Artes con Chopiniana — una nueva denominación de Las silfides-, a la que se sumaron un Pas de trois de Gaetano Donizetti, Fiesta de primavera sobre la ópera de Hamlet con partitura de Ambroise Thomas y Coppélia, de Leo Delibes. ${ }^{36}$ Esta última se llevó de gira al Teatro Variedades de Puebla a principios del mes de abril. ${ }^{37}$ La prensa destacó la "extraordinaria gracia” de Maruja Bardasano entre el resto de componentes del cuerpo de baile. ${ }^{8}{ }^{8}$ En el citado

34. Амв, programa de mano, Ballet Nelsy Dambre, Teatro Lerdo, Xalapa, I4 de diciembre, s.a.

35. Últimas Noticias, 22 de febrero de 1951. Citado en Tortajada Quiroz, 75 años de danza, 125. 36. Амв, programas de mano, Ballet Nelsy Dambre, Palacio de Bellas Artes, México, D.F., 2I y 23 de febrero de 195I. Véase la crónica en Últimas Noticias, 22 de febrero de 1951. Citado en Segura, Nelsy Dambre, I34-I35.

37. амв, programa de mano, Ballet Nelsy Dambre, Teatro Variedades, Puebla (3 de abril de 195I [tachado y escrito a mano: domingo 8]).

38. Амв, "Bella fiesta de ballet, con la señorita Lupe Serrano", Excélsior, 23 de febrero de I95I, s.p. 
programa, por primera vez y por cortesía del Ballet de la Ciudad de México, apareció Felipe Segura. ${ }^{39}$ El bailarín había logrado una brillante formación al haber tomado clases con maestros nacionales e internacionales. Su participación como artista invitado en la agrupación de Dambre fue su primer paso para llevar a cabo tareas en la dirección en ańos posteriores. ${ }^{40}$

Otro de los responsables de la danza del momento era Carletto Tibón, un artista de procedencia italiana que había trabajado en La Scala de Milán, a pesar de no haber recibido una formación especializada en ballet. Según recordaba Felipe Segura, Tibón pidió a Dambre la colaboración de sus bailarines para las coreografías de las temporadas de ópera. ${ }^{4 \mathrm{I}}$ Así, Maruja se subió al escenario del Teatro Arbeu de la capital como integrante del cuerpo de baile de La viuda alegre..$^{42} \mathrm{El}$ I8 de mayo de 195I, de nuevo bajo la autoría de Tibón, la compañía interpretó las piezas bailadas del Gran Concierto de Gala con música de Giuseppe Verdi — con fragmentos de Nabucco, Los lombardos, La fuerza del destino, Las vísperas sicilianas y El himno de las naciones-, que tuvo lugar en el escenario del Palacio de Bellas Artes. ${ }^{43}$ En el desaparecido Teatro Colón, entre mayo y junio de 1951, el Ballet de Nelsy Dambre ofreció un programa formado por las piezas más conocidas: Las silfides, Cisne negro, Coppélia, Ballet húngaro, Mozartiana, Hamlet, Pas de trois y nuevas apuestas: Bolero rítmico — sobre la composición de Federico Longas_ - y Troyana — con partitura de Jules Massenet y coreografía de César Bordes. ${ }^{44}$ La prensa destacó la "bella silueta" de Maruja Bardasano entre los cisnes del cuerpo de baile. ${ }^{45}$ Por último, para concluir la participación de la bailarina madrileña en las piezas

39. Alejandrina Escudero, Felipe Segura: una vida en la danza (México: Consejo Nacional para la Cultura y las Artes/Instituto Nacional de Bellas Artes, 1995).

40. Segura, Nelsy Dambre, I27.

4I. Segura, Nelsy Dambre, I49.

42. Амв, "Cumpleaños de Marouka Bardasano", s.f., у амв, Bambi, "Historia que comienza mañana", recortes de prensa.

43. Амв, programa de mano, Gran Concierto de Gala, Palacio de Bellas Artes, México, D.F., I8 de mayo de I95I.

44. En este programa, el nombre de Tibón se sustituyó por el de Felipe Segura. El I3 de julio el Ballet de Nelsy Dambre, dirigido por Felipe Segura, llevaba Las sílfides y Troyana al Auditorio Justo Sierra de Toluca. Amb, programas de mano, Ballet Nelsy Dambre, Teatro Colón, México D.F., 3 y io de junio de I951; programa de mano, Ballet Nelsy Dambre, Auditorio Justo Sierra, Toluca, I3 de julio de 195 I.

45. амв, Arturo Mori, "Escenario y platea", Últimas Noticias, México, D.F., 30 de mayo de I95I, s.p. 
con autoría de Tibón, se mencionan las coreografías de las óperas representadas en el Palacio de Bellas Artes a partir del verano de i951: Adriana Lecouvreur, de Francesco Cilea, y Aida, de Giuseppe Verdi. ${ }^{46}$

En el otoño de ese año, el Ballet de Nelsy Dambre actuó en el Teatro Degollado en varias ocasiones. Por un lado, el 28 de septiembre se presentó Rigoletto como parte de las celebraciones de su centenario, gracias a la organización de la Unión de Cronistas de Teatro y Música y el Comité Verdi de México, D.F. ${ }^{47}$ Por otro lado, a principios de octubre, y en beneficio de la Casa de la Niña Obrera, se representaron entre otros el Ballet húngaro, de André Messager, Blanco y negro, de Jules Massenet, El espectro de la rosa, de Carl Maria von Weber, Adagio y variación, de Giuseppe Verdi, la Sinfonía clásica de Sergei Prokofiev, Mozartiana y algunas piezas pasadas, como El Cascanueces, El lago de los cisnes, Chopiniana y Hamlet. ${ }^{48}$ El 28 de diciembre de 1951, el coreógrafo italiano también fue el responsable de los bailes de la opereta El murciélago, de Johann Strauss, una exitosa representación bajo la dirección de Ernesto Roemer y su Compañía Lírica de Grandes Cantantes de Ópera, organizada en el Teatro Colón de la capital. ${ }^{49}$

A pesar de estas numerosas representaciones y de la calidad de sus propuestas, el mantenimiento de la compañía era muy costoso, algo que, como se apuntó ya, denunciaba constantemente la prensa.50 Así lo recogió el crítico Arturo Souto Alabarce en I95I en las páginas de la revista Segrel:

Con todo, los bailarines que forman el Ballet Nelsy Dambre no cuentan hasta ahora con ninguna subvención. Es el entusiasmo, la fe y el amor por su carrera — sentimientos propios de los auténticos artistas - lo que les impulsa a trabajar mańana y tarde, día tras día, sin más recompensa que la propia satisfacción y el reconocimiento y el aplauso del público que los admira.

Como parte entusiasta de este último, Segrel se une fraternalmente al esfuerzo de este cuerpo de baile que lleva por nombre el de su maestra, Nelsy Dambre, nombre

46. АмB, programas de mano, Ópera Nacional A.C., Palacio de Bellas Artes, México, D.F., 30 de junio y Io de julio de I95I.

47. Амв, programa de mano, Rigoletto, Teatro Degollado, México, D.F., 28 de septiembre de 195 I.

48. Амв, programas de mano, Ballet Nelsy Dambre, Teatro Degollado, México, D.F., 6 a 8 de octubre [1951].

49. Амв, programa de mano, El murciélago, Teatro Colón, México, D.F. [I95I].

50. El Universal, México, D.F., 2 I de febrero de 1951; Últimas Noticias, México, D.F., 22 de febrero de 1951. Citado en Segura, Nelsy Dambre, I33-136. 
que señala el comienzo de una tradición en nuestra ciudad, y confía en que pronto le será concedida una subvención oficial —indispensable para poder sostener un esfuerzo de esta naturaleza - y, por lo que respecta a los directores del Palacio de Bellas Artes, estamos seguros que, atendiendo al deseo de todos los aficionados, organizarán una temporada completa con el Ballet Nelsy Dambre, y no se limitarán a presentarlo en unas cuantas funciones esporádicas como hasta ahora han hecho. Todo lo cual, será para honra y fama del arte mexicano. ${ }^{51}$

La Revista Continente insistía en la misma línea, subrayando que la labor de Dambre era "digna de consideración, teniendo en cuenta que carece de toda ayuda privada u oficial, contrastando con otras escuelas o academias oficiales o semioficiales que a pesar de fuertes subsidios, su labor se reduce a impartir clases problemáticamente efectivas y que no realizan ningún trabajo objetivo que sirva para popularizar el ballet de nuestro público, ávido de ello y apto para entenderlo".52

A pesar de estas llamadas de atención, las demandas del mundo cultural mexicano no se cumplieron, de manera que Nelsy Dambre decidió abandonar México para instalarse en El Salvador, donde el gobierno había prometido apoyar su nuevo proyecto. ${ }^{53} \mathrm{La}$ fiesta de despedida de la coreógrafa tuvo lugar precisamente en la casa de los Bardasano y a ella acudieron importantes figuras de la danza mexicana del momento, desde Lupe Serrano y Guillermo Keys hasta Carletto Tibón y César Bordes. ${ }^{54}$ Felipe Segura recordaba aquella fiesta en el estudio que dedicó a la maestra francesa:

El Is de mayo, en la hermosa mansión del maestro José Bardasano, papá de Marouka, hubo una fiesta para despedir a Madame Dambre. Fiesta con mucha comida porque los bailarines comíamos como tigres, poca bebida porque sólo los mayores la consumían, pero sí hubo champaña para Madame. Entre las diversiones Tomás Seixas imitó a Madame Dambre impartiendo clase, en calcetines y con su acento francés. También hubo imitaciones de Carletto Tibón, a quien llamaban el "maestro T-Bone

5I. Arturo Souto Alabarce, "El ballet Nelsy Dambre", Segrel, núm. 2 (junio-julio, I95I): 23.

52. Ricardo Mondragón, Revista Continente (febrero, 195I). Citado en Segura, Nelsy Dambre, I39-I40.

53. Mitchel Snow, "Dance on the Path of Life", The Free Library, Organization of American States, 1994, http://www.thefreelibrary.com/Dance+on+the+path+of+life.-aor6444436, consultado el 29 de septiembre de 2014.

54. Амв, "Bulliciosa fiesta en casa del pintor José Bardasano", s.f., recorte de prensa. 
Steak", y de Margarita Parlá. Deborah y Tomás bailaron un tango apache. Ésta fue una de las muchas fiestas que tuvimos; cualquier pretexto era bueno para reunirnos, y no solamente asistían los miembros de la compañía, tengo fotografías donde están bailarines de otras ramas y actores [...]; verdaderamente la pasábamos bien juntos. 55

Para cuando Dambre se marchó de México otro importante coreógrafo y maestro ya marcaba la carrera de Maruja Bardasano: el entonces director general de la compañía Sergio Unger (fig. 5). Éste era un antiguo miembro del famoso Original Ballet Russe, que decidió quedarse a residir en México en 1942, cuando su grupo pasó por allí de gira. Gracias a estas experiencias, había aprendido en un ambiente en el que se conservaron las enseñanzas de grandes figuras, como Sergei Diaghilev o Ida Rubinstein, lo que le permitió implantar el legado de aquel modelo de ballet ruso en su etapa mexicana. Así, además de trabajar con Nelsy Dambre, colaboró puntualmente en el Ballet Chapultepec y poco después denominó a su agrupación el Ballet Concierto. ${ }^{56}$ En los primeros momentos desarrolló de manera simultánea la dirección y compartió lecciones y programas con su amigo y antiguo compañero del Original Ballet Russe, Michel Panaieff, con quien Bardasano también tomó clases. Panaieff provenía de una familia de emigrados rusos; fue bailarín principal de la Ópera de Belgrado a mediados de los años treinta, hasta que lo contrataron en el Ballet Russe de Monte Carlo y luego en el Original Ballet Russe. Tras la segunda guerra mundial, pasó por Estados Unidos, donde lo conoció Felipe Segura en su estancia en Hollywood. El bailarín mexicano le ofreció organizar un curso en su tierra, lo que acabó por propiciar su instalación y su trabajo en el seno del Ballet Concierto hasta $1953 .{ }^{57}$

Maruja Bardasano actuó con este grupo como solista en el programa del teatro de Bellas Artes el I8 de octubre de 1952 en una representación patrocinada por las Juventudes Musicales de México y la colaboración de la Orquesta Sinfónica Nacional a las órdenes de José Pablo Moncayo, un programa que se

55. Segura, Nelsy Dambre, I45.

56. Tortajada Quiroz, 75 años de danza, i38. En la compañía, Maruja Bardasano compartió cartel con otros reputados bailarines: Felipe Segura, Laura Urdapilleta, Sonia Castañeda, Armida Herrera, Cora Flores, Martín Lemus, Tell Acosta. La compañía permaneció activa hasta 1963, aunque para entonces la bailarina madrileńa ya había retornado a España.

57. "Michel Panaieff, 69, Teacher and Dancer for Ballet Russe", The New York Times, 24 de febrero de 1982; Segura, Nelsy Dambre, I65-I66 y 196. 
5. Clase de danza de Sergio Unger, a la derecha, Maruja Bardasano. Foto: Emilio. Colección Maruja Bardasano.

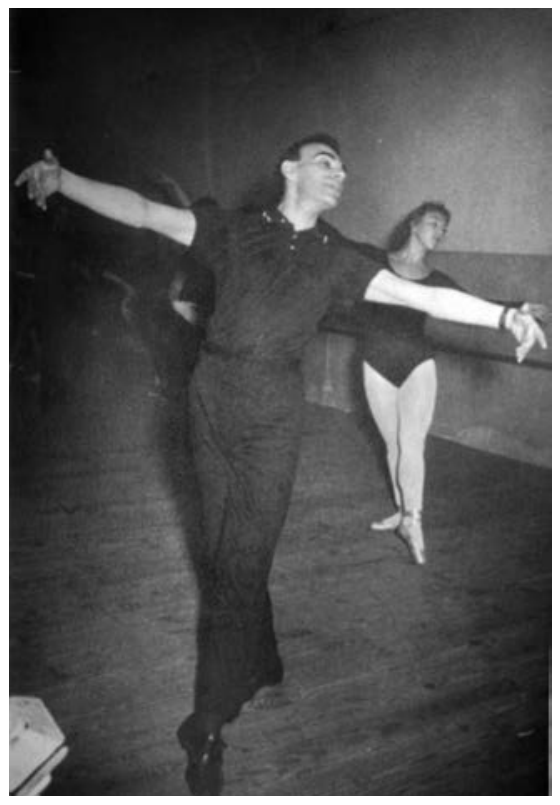

repitió en la Sala Chopin el 6 de diciembre. ${ }^{58}$ Éste se compuso de los siguientes números: El espejo, con coreografía de Panaieff, en el que Maruja Bardasano interpretó el solo de la tercera variación, y la Danza de los mirlitones de El Cascanueces (fig. 6), ambos con música de Chaikovski, así como El cinturón del diablo de Dvorak, con coreografía de Panaieff. Sobre este programa, la crítica señaló "momentos de gran sensibilidad e intenso placer"s9 en los que Bardasano "llenó la escena con su alegría rubia y sus arabescos y pirouettes". ${ }^{60} \mathrm{La}$ madrileña también fue solista de piezas como Serenata, con música de Wolfgang Amadeus Mozart, y Ópera, de Johannes Brahms, ambas con coreografía de Unger y un elenco compartido con Déborah Velázquez, Aurora Bernard, Tomás Seixas, Francisco Arainza y Martín Lemus. Destacó igualmente en Ballet Fausto, con partitura de Gounod y montaje de Unger y Jorge Cano, en el

58. АмB, programa de mano, Ballet Concierto, Palacio de Bellas Artes, México, D.F., I8 de octubre de 1952; Segura, Nelsy Dambre, 195.

59. Luis Arriola, "Ballet. Serge Unger presentó a Sonia Castañeda con El cisne negro", Cine Mundial, 4 de abril de 1955. Citado en Tortajada Quiroz, 75 años de danza, I64.

6o. Tortajada Quiroz, 75 años de danza. 


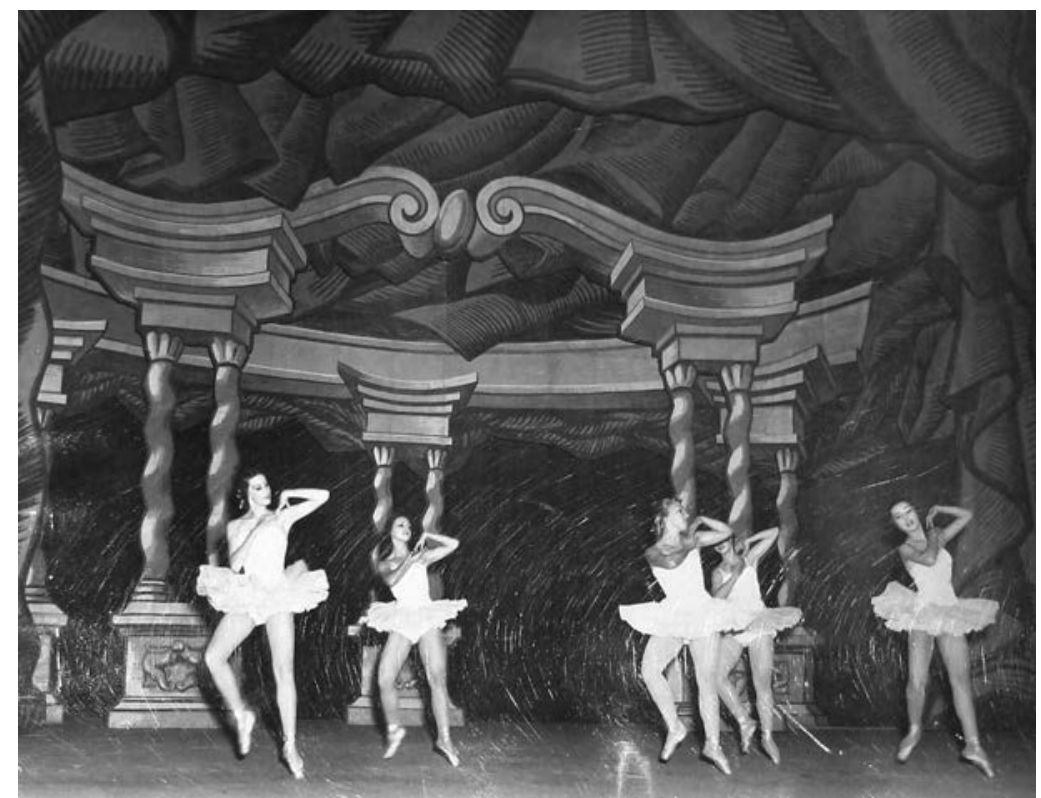

6. Representación de la Danza de los mirlitones de El Cascanueces por el Ballet Concierto, I952. Maruja Bardasano es la tercera de izquierda a derecha. Colección Maruja Bardasano.

que protagonizó el quinto número con un pas de deux con el propio Cano. ${ }^{61}$ Estas representaciones estaban patrocinadas por el Círculo de Bellas Artes y el Inba y contaban de nuevo con la interpretación musical de la Orquesta Sinfónica Nacional.

En 1953 Michel Panaieff logró sacar adelante el proyecto de difundir algunas de las piezas del repertorio del Ballet Concierto por televisión. Así, en el mes de enero se retransmitió la pieza Carnaval español, en el programa del Concierto General Motors, en la que los bailarines llevaron el vestuario tradicional de ballet con detalles "a la española", como chalecos cortos, guiños a los trajes de luces y flores en el pelo. El mes siguiente repitieron la experiencia con la Danza húngara, en la que también se jugó con los elementos folclóricos y las bailarinas sustituyeron las puntas por los zapatos de carácter.

6I. АмB, programa de mano, Ballet Concierto de Sergio Unger, Palacio de Bellas Artes, México, D.F., 25 de enero, s.a. 
El año 1954 comenzó con una actuación del Ballet Concierto en el Círculo de Bellas Artes (figs. 7 y 8), donde Maruja Bardasano apareció en los programas como primera bailarina. ${ }^{62}$ En el mes de marzo la compañía volvió a ofrecer una representación en el Palacio de Bellas Artes, patrocinada por las Juventudes Musicales de México, con la Orquesta Sinfónica Nacional —esta vez dirigida por Salvador Contreras - y las apariciones estelares de Laura Urdapilleta, Socorro Bastida, Jorge Cano y Tomás Seixas. ${ }^{63}$ El repertorio englobó los siguientes números coreografiados por Unger: El lago de los cisnes, en el que Maruja Bardasano aparecía como uno de los cisnes del cuerpo de baile, La doncella y el diablo, de Franz Liszt, en el que interpretaba a una de las amigas, y de nuevo la pieza Ópera. ${ }^{64}$ La temporada siguiente, la compañía realizó una gira por México y, entre otros lugares, pasó por Monterrey en el otoño de 1954, donde actuó en el Teatro Florida. ${ }^{65}$ Allí se agasajó a los artistas con una gran recepción organizada por José Salinas Iranzo. ${ }^{66}$ A raíz de las representaciones, el crítico Fedres destacó la intervención de Maruja y Seixas, "una pareja encantadora”, en Serenata, mientras que Jesús Ángel Martínez subrayó la "alegría indescriptible" de la bailarina - que interpretó a la protagonista- en Campirana, una obra con partitura de Meyerber, vestuario de Xavier Lavalle y coreografía de Sergio Unger. ${ }^{67}$ En el mismo programa se presentaron las Variaciones románticas de Franz Schubert, una coreografía de Unger y Segura con vestuario según las litografías de Chalon, donde Maruja bailó con sus compañeras Cora Flores, Alicia Pineda, Déborah Velázquez, Ana María

62. Амв, Alberto Catani, "Teléfono", recorte de prensa, 24 de enero de 1954, 2.

63. АмB, programa de mano, Ballet Concierto, Palacio de Bellas Artes, México, D.F., I3 de marzo de 1954 .

64. Véase la fotografía en la que posa para la prensa con el traje de Serenata, Excélsior, 7 de febrero de 1954 .

65. A estas giras, a Maruja la acompañaba su tía Clara Juana García González, a quien Unger encomendaba llevar los fondos de la compañía.

66. Salinas Iranzo fue un exiliado espańol fundador de la empresa Vinícola del Norte y un gran coleccionista de la obra de José Bardasano (Alicia Alted, La voz de los vencidos. El exilio republicano de 1939 [Madrid: Aguilar, 2005]). "La nueva presentación de la ópera Fausto, la tarde de ayer, en el Teatro Florida, resultó maravillosa", El Norte, 23 de octubre de 1954, 2; "Elegante recepción a los artistas de la Ópera ofrecida por el Sr. Salinas Iranzo", El Porvenir, 27 de octubre de 1954, I.

67. Амв, programa de mano, Ballet Concierto, Ateneo Fuente, Saltillo, Coahuila, 23 de octubre de 1954, s.p.; Fedres, "El Ballet Concierto de Unger", El Porvenir, 27 de octubre de 1954, I; Jesús Ángel Martínez, "Brillante actuación del Ballet Concierto de México", El Sol, 24 de octubre de 1954, s.p. 


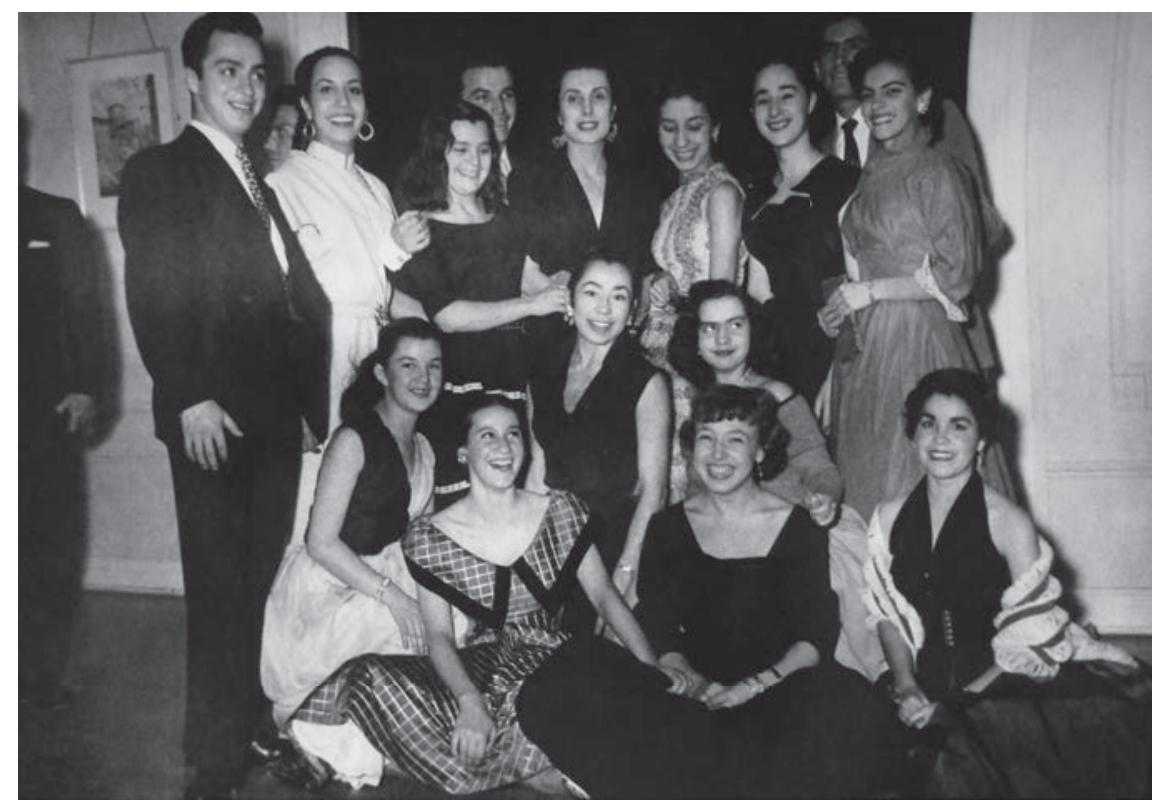

7. Miembros del Ballet Concierto en el Círculo de Bellas Artes, México, D.F., I954. Maruja Bardasano está sentada en la primera fila, segunda de izquierda a derecha. De pie se reconoce, en el mismo orden, a Armida Herrera (segunda), Felipe Segura (cuarto) y Tamara Toumánova (al centro). Colección Maruja Bardasano.

Cardús y Raymunda Arechavala. Asimismo, en 1955 la artista participó en una gran puesta en escena de El pájaro azul, un cuento de Maurice Maeterlinck con música de Chaikovski, coreografía de Unger y escenografía de Antonio López Mancera, dirigido por André Moreau y organizado por el InBA. ${ }^{68}$

Unos meses más tarde Sergio Unger y Felipe Segura presentaron un nuevo programa, esta vez sobre el escenario del Nuevo Teatro Fábregas, que se estrenó el 19 de mayo de 1956. ${ }^{69}$ Sus números comprendieron, entre otros, las Variaciones románticas, de Franz Schubert, y una reposición de El lago, en la que Maruja Bardasano volvió a vestir de cisne. También en el seno del Ballet Concierto

68. Амв, programa de mano, El pájaro azul, Instituto Nacional de Bellas Artes, México, D.F., 1955 .

69. Амв, programa de mano, Ballet Concierto de México, Nuevo Teatro Fábregas, México, D.F., I9 de mayo, 1956. 


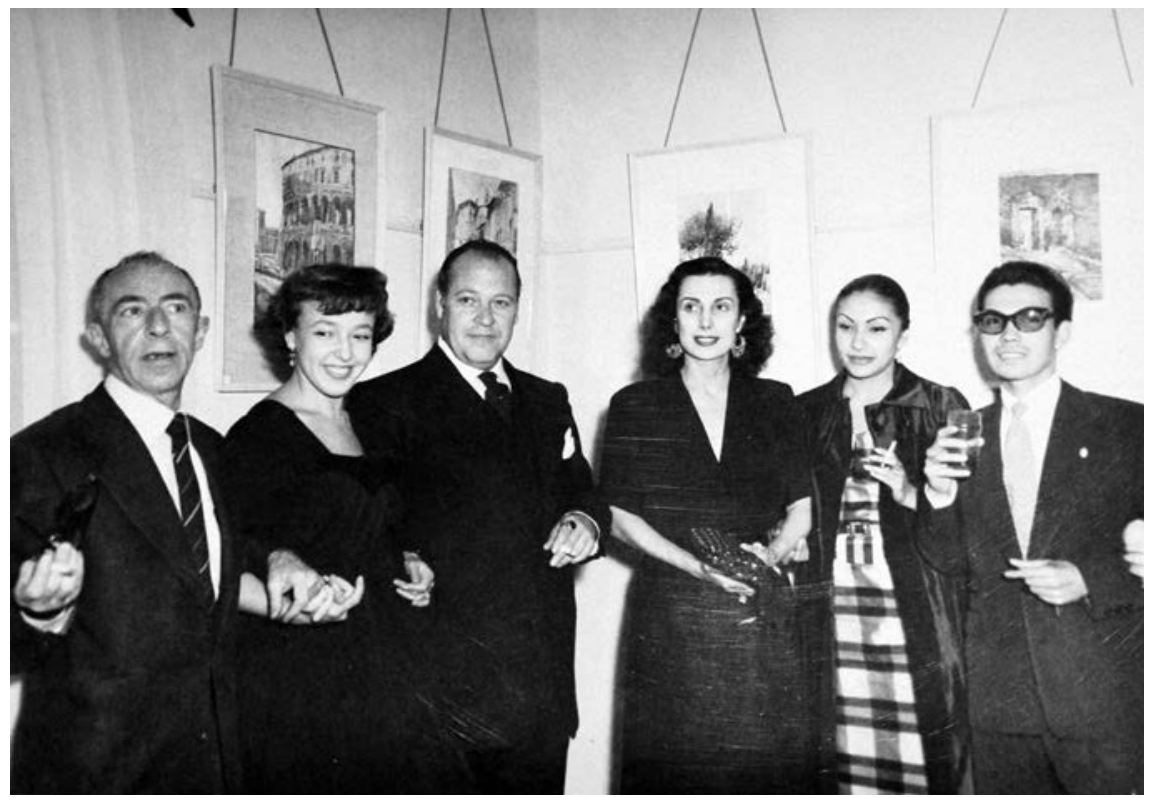

8. Inauguración en el Círculo de Bellas Artes, México, D.F., I954. En la foto, de izquierda a derecha, Sergio Unger, Maruja Bardasano, José Bardasano Baos, Tamara Toumánova, Socorro Bastida y Martín Lemus. Colección Maruja Bardasano.

se presentaron otras piezas: La manda, Suite italiana, Al aire libre, El Chueco y una reposición de las danzas de Giselle que denominaron Fiesta, de Delibes. ${ }^{70}$

Aunque, como se puede comprobar, los programas estaban de nuevo formados por los mismos clásicos europeos, poco a poco las puestas en escena iban mejorando, al cuidado del Departamento de Producción del InBA. A pesar de ello, seguían reutilizando telones comodín albergados en los almacenes del teatro, que pasaban de uno a otro espectáculo sin grandes signos de innovación estética: la escena del bosque, el pueblecito pintoresco, la arquitectura palaciega, entre otros. Fue hasta el estreno de piezas puntuales más originales cuando la compañía contó con escenógrafos externos. No en vano, como ha estudiado a profundidad Alberto Dallal, la gran revolución escenográfica en el medio mexicano llegó ligada al surgimiento del Movimiento Mexicano

70. Амв, Víctor Reyes, "La semana musical”, s.f., recorte de prensa. 
de Danza Moderna (1940-1965)..$^{71}$ Eran por tanto los espectáculos más renovadores desde el punto de vista del vocabulario coreográfico los que contaron también con una preocupación por los elementos plásticos que, sin embargo, muchas veces no acababan de aplicarse al repertorio del ballet clásico. Como excepciones, en el seno del Ballet Concierto podemos destacar la participación de algunos jóvenes escenógrafos, como Antonio López Mancera y Manuel Meza.72 Por ejemplo, en los números Rendez-vous (I952), con la partitura de la Suite Holberg, de Edvard Grieg, y las Danzas campesinas de Giselle (1956) el vestuario fue diseñado por Xavier Lavalle, mientras que el Pas de deux de Don Quijote (1956) y la interesante pieza Fuego muerto (1956) contaron con un figurinismo de Luis Sánchez Arriola. ${ }^{73}$

La pintora madrileńa recuerda que en algunas ocasiones sus padres, José Bardasano y Juana Francisca Rubio, ayudaban aconsejando y orientando desde un punto de vista plástico en las puestas en escena de los ballets. ${ }^{74}$ Especialmente su madre diseñó y confeccionó alguno de los trajes que Maruja vistió en sus representaciones, como el de Giselle (fig. 9), al tiempo que realizó dibujos de los personajes que su hija interpretaba sobre las tablas con una brillante maestría o protagonistas femeninas de las representaciones de entonces, como Julieta, Mariana Pineda, una chulapa, una maja, entre otros. ${ }^{75}$

Al seguir estos mismos pasos y aunando sus dos pasiones, la propia Maruja Bardasano se introdujo en el mundo de la escenografía para ballet con la obra La noche de Walpurgis, en la que también apareció como bailarina. ${ }^{76} \mathrm{Se}$ trataba de un fragmento de la ópera Fausto, de Charles Gounod, con coreografía montada por Sergio Unger y Jorge Cano, estrenada durante una gira en el Teatro de la Paz de San Luis Potosí el 26 de abril de 1956, un programa en el que Maruja también formó parte del elenco de Las silfides y las Danzas cam-

7I. Alberto Dallal, "Los ojos del escenario. Escenógrafos de la danza mexicana”, Anales del Instituto de Investigaciones Estéticas XXXII, núm. 96 (20I0): 58.

72. Programa de mano del Ballet Concierto de México, Teatro Degollado, Guadalajara, 7 de septiembre, 1958. Archivo Vertical. Centro Nacional de Investigación, Documentación e Información de la Danza José Limón/Instituto Nacional de Bellas Artes, México, D.F.

73. En la mayoría de los programas se señala que la iluminación corría a cargo de Ricardo Cedillo, la tramoya, de Marcelino Jiménez y la utilería, de Francisco Pérez.

74. Entrevistas de la autora a Maruja Bardasano, Madrid, 9 y 23 de marzo de 2010.

75. El Амв conserva fotografías de estas ilustraciones realizadas en I95I por los hermanos Mayo.

76. Ana María Arias de Cossío e Idoia Murga Castro, Escenografía en el exilio republicano: teatro y danza (I936-I975) (Sevilla: Renacimiento) (en prensa). 
9. Maruja Bardasano, caracterizada como Giselle con el vestido diseńado por Juana

Francisca Rubio. Colección Maruja Bardasano.

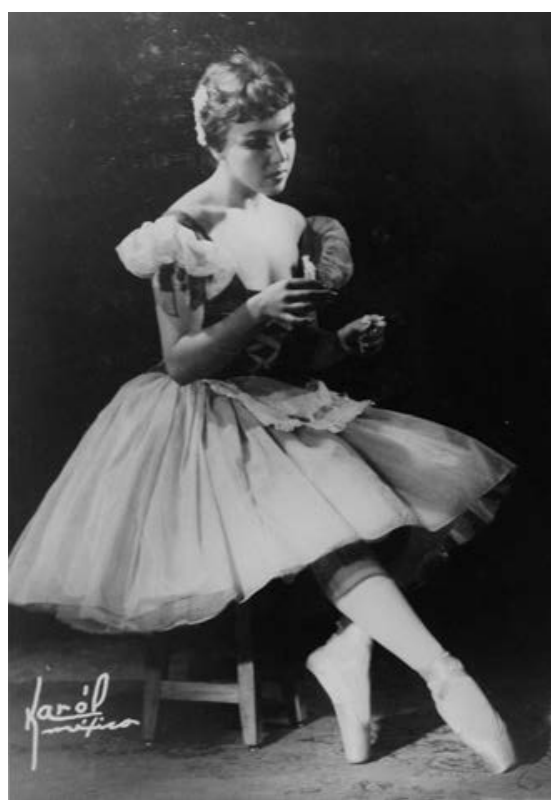

pesinas de Giselle. ${ }^{77}$ Aunque su misión como diseñadora fue una novedad y un incentivo para la artista, el figurinismo no le atrajo tanto la atención como para repetir la experiencia en los años sucesivos. ${ }^{78}$ Por desgracia, hasta el momento no se ha encontrado más información acerca de esta labor escenográfica de la artista, quien tampoco ha conservado en su archivo personal registros visuales suficientes con los que llevar a cabo un análisis a profundidad. ${ }^{79}$ De cualquier manera, el éxito de la pieza fue tal que continuó en el repertorio del Ballet Concierto entre 1959 y 1960 en las programaciones del Palacio de Bellas Artes ${ }^{80}$

77. Амв, programa de mano del Ballet Concierto de México, Teatro de la Paz, San Luis Potosí, 29 de abril de 1956.

78. Más adelante, ya en Madrid, en algunas ocasiones Maruja Bardasano ejerció de diseñadora de modas al idear los vestidos de amigas y conocidas que luego confeccionaban en una sastrería.

79. En las distintas entrevistas que hice a la artista ella no dio más referencias a dicha intervención, una colaboración puntual en el conjunto de su trayectoria.

80. Archivo Vertical-cenidi Danza/Instituto Nacional de Bellas Artes, programa de mano del Ballet Concierto de México, Auditorio Nacional, México, D.F., is de marzo de 1959. 


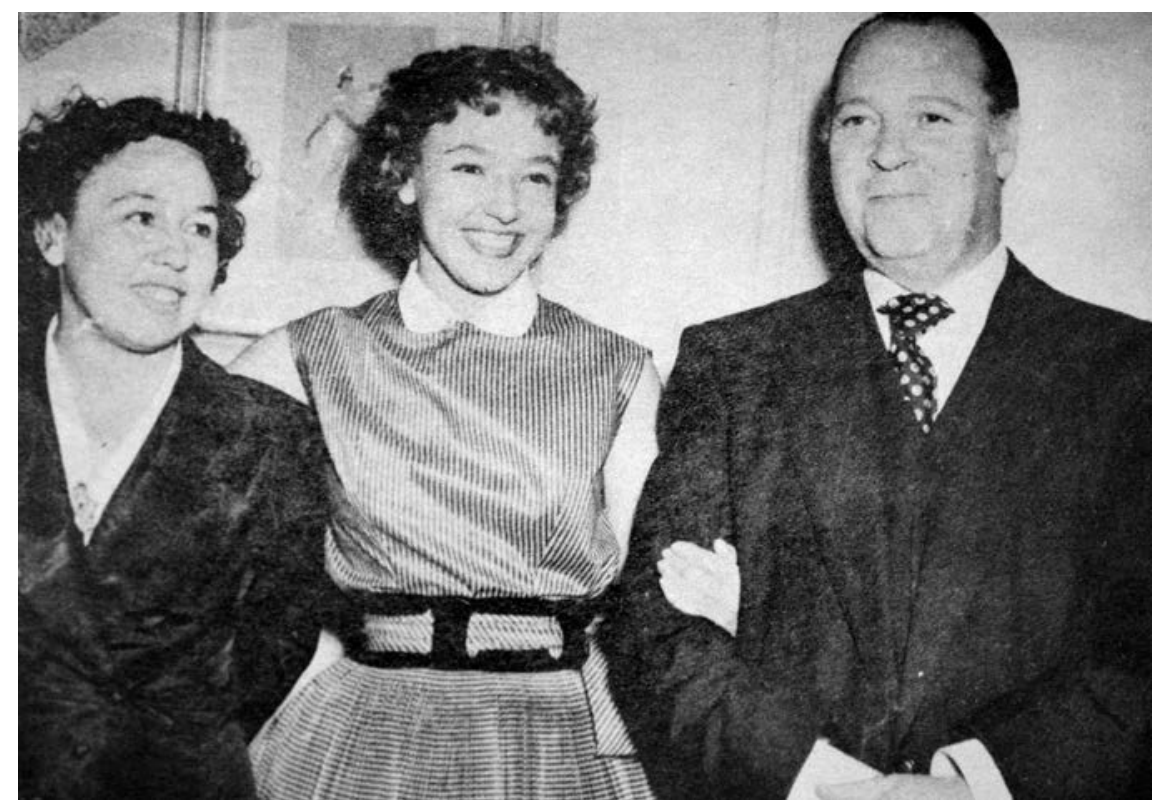

Io. Maruja Bardasano con sus padres, Juana Francisca Rubio y José Bardasano Baos, en la inauguración de su exposición en el Círculo de Bellas Artes, México, D.F., 1955. Colección Maruja Bardasano.

y de algunas giras realizadas por la compañía, ${ }^{8 \mathrm{I}}$ aunque para entonces la artista ya había decidido retornar a Espańa y prácticamente —como se dice en el argot de la danza- "colgar las zapatillas".

Poco antes y volcada en su faceta plástica, Maruja Bardasano protagonizó su primera exposición individual en el mencionado Círculo de Bellas Artes de México, que se inauguró el is de abril de 1955 (figs. Iо y ir). ${ }^{82}$ Se trataba de una importante institución en cuya fundación en 1945 había tenido mucho que ver

8I. La obra se representó, por ejemplo, en el marco del Festival de Promoción Cultural y Artística del Municipio de Acapulco en el Fuerte de San Diego el 4 de marzo de 1960; en el Auditorio del Instituto de Ciencias Autónomo de Zacatecas, el I3 de mayo de 1960; en el Gran Teatro Degollado, el 2I de mayo de 1960; y en el Gran Teatro de la Paz de San Luis Potosí, el 27 de mayo de 1960. Archivo Vertical-cenidi Danza/Instituto Nacional de Bellas Artes, programas de mano.

82. Las fotografías del evento las realizaron los hermanos Mayo, grandes amigos de la familia Bardasano. 
II. Folleto de la exposición de dibujos de Maruja Bardasano en el Círculo de Bellas Artes con ilustración de Juana Francisca Rubio, 1956. Colección Maruja Bardasano.

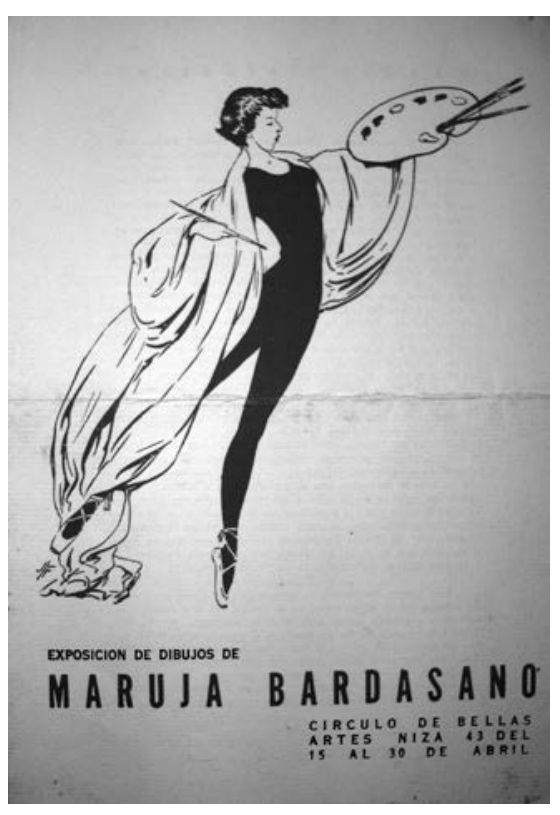

su padre, en colaboración con otros españoles, como Juan Eugenio Mingorance, Gerardo Lizárraga, Francisco Camps Ribera y Carlos Ruano Llopis. ${ }^{83}$ Situado inicialmente en el vestíbulo del Cine Magerit de la capital, poco después se trasladó a la calle Niza número 43. Siempre estuvo dedicado a la promoción de las artes y a apoyar el desarrollo de la cultura española en el exilio mexicano, y fue — en palabras de Justino Fernández — "la organización privada más activa" ${ }^{84}$

En este contexto, la muestra de la joven Maruja llamó la atención de los periodistas precisamente por el interesante vínculo que comenzaba a perfilarse en su producción entre la pintura y la danza. Así, por ejemplo, en los recortes de prensa se recogía que la artista había heredado las facultades pictóricas de su padre, "en sus cuadros revela que tiene un brillante porvenir en el manejo de los matices y los pinceles. La danza ha sido para Maruja su más grande afición". ${ }^{85}$ Pero además de las "figuras" y "posturas de ballet”, los diarios des-

83. Cabañas Bravo, Rodríguez Luna, iı9.

84. Justino Fernández, "Catálogo de exposiciones de arte en 1946”, suplemento núm. I5 de Anales del Instituto de Investigaciones Estéticas (1947): 6.

85. Амв, "Personajes del Ballet dirigido por S. Unger", recorte de prensa [1956]. 
tacaban su mirada a la realidad, "una realidad plástica y graciosa, como la de esas inditas que se presentan ante uno en la calle con andares grávidos de un paso ancestral, solemne y delicado". ${ }^{86}$ Otros, como Antonio de la Villa, auguraban todos los honores a una exposición que haría época, al tiempo que alababan sus últimas actuaciones sobre el escenario:

Rubia como las candelas: ojos grandes, dulces, que dicen todo lo que lleva dentro; evocación de aquella primaveral Flérida del tierno poeta Garcilaso, uniendo en la delicadeza de la figura, originalidad y naturalidad en sus realizaciones, que amén de ser una bailarina suprema es una pintora excelsa. Ésta es Maruja Bardasano, la madrileñísima Maruja, que de casa le viene, ya que sus padres son pintores de altos vuelos y ella tenía que seguir la línea de sus padres, en el retrato, y en escenas de ambiente. [...] Todo no está, en materia de baile, en esas mudanzas con los pies, bien de plano o de punta; en los destaques; en el juego de cintura y manejo de los brazos, está en el sentimiento, en el modo de concebir, que es calidad y cualidad de Maruja Bardasano, la juvenil muñequita rubia. El baile cuanto menos mecánico pueda ser, es más baile. ${ }^{87}$

Muchas de las obras expuestas en el Círculo eran escenas de aquellos ballets interpretados por la propia artista, sus personajes y sus momentos de trabajo cotidiano: Descanso, Ensayo, Intermezzo, Thais, Romance, Venecia, Recoco, Czardas, Viejo, Coqueta, Chinitos, Ópera (fig. I2), Pas de deux, Chulapa, La pintora, Baile de graduados, Sheherezada, Papá Noel, Coppélia, Indita, Estampa romántica, Mixteca, Estampa pasada, Estampa medieval, Oriental, Nochebuena en Veracruz, Oaxaqueña, Las silfides.

El objetivo de aquel evento, según contó su protagonista, era vender algunas obras que le permitiesen realizar un viaje por Europa "para estudiar, contrastar y seguir mis ensayos de danza, que son mi obsesión y en lo que no he de parar hasta vencer en todo lo que pretendo" ${ }^{88}$ El éxito fue tal que prácticamente el público adquirió todas las obras expuestas, localizadas en la actualidad en colecciones particulares dispersas, circunstancia que dificulta el estudio pormenorizado de la obra plástica de juventud de la artista. El folleto que acom-

86. Expediente Bardasano-Biblioteca de las Artes-Centro Nacional de las Artes, recorte de prensa.

87. Амв, Antonio de la Villa, "Colonia española", recorte de prensa [I955]. Véase también la crónica de Catai, "Exposición de dibujos de Maruja Bardasano", recorte de prensa [I955]. 88. De la Villa, "Colonia española". 
I2. Maruja Bardasano, Ópera, I955. Colección particular.

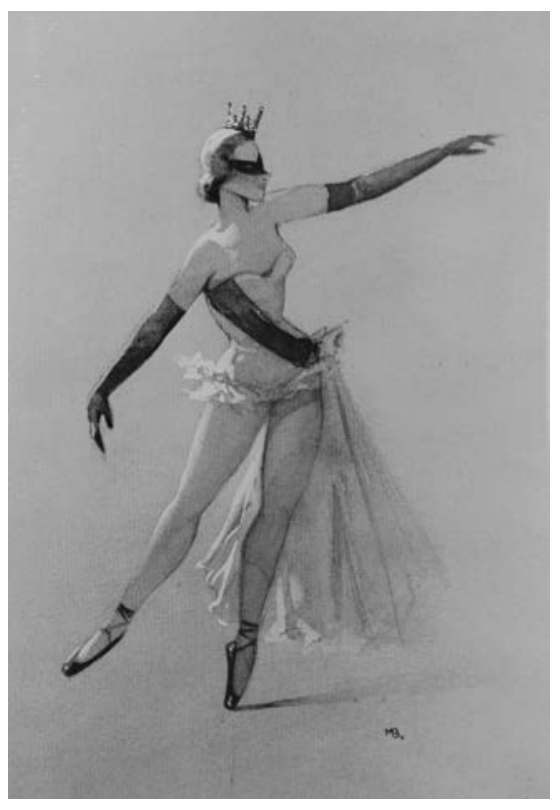

pañaba la exposición presentaba un bello retrato de Maruja, realizado por su madre, en el que aparecía ejecutando un arabesque en punta con la paleta y el pincel en las manos (fig. II). ${ }^{89}$ En su interior se recogía una semblanza que le dedicó el poeta exiliado Alfonso Camín, que merece la pena reproducir a pesar de su extensión:

Maruja Bardasano. ¿Habéis oído un cantar? Porque Maruja Bardasano es un cantar y un color. La alondra madrileña se embriagó de mar y de azul y la tenemos en casa. Como María Casares crece en París, Maruja Bardasano crece y florece en México. Las dos son únicas en lo suyo, una en el drama y otra en el ballet, voces de España perdidas que ya no recoge España, pero que las recoge el mundo. [...] Y así como nos asombró ayer Maruja Bardasano en la escena con su deslumbrante armonía de carne y hueso, de luna y de mar, de sol y de espigas, la madrileńita nacida en la Plaza de Santo Domingo, cara a Preciados y a San Bernardo, a Leganitos y a los almendros de la Plaza

89. Амв, folleto de la "Exposición de dibujos" de Maruja Bardasano, Círculo de Bellas Artes, México, D.F., abril de 1955 . 
de España, se presenta ahora con lo que es en ella raíz de naturaleza, pintora desde el vientre y la galladura, como la paloma es paloma desde que sale del huevo. Pintora la madre, pintor el padre, negarle a ella el don del color y de la gracia, sería tanto como negarle a la alondra el horizonte azul de las Espańas y el crecer y el granar de la espiga. [...] Mexicana y española y por ende madrileña, es la gentil Maruja Bardasano, finísima mujer en el arte, que en un Is de abril de nuestro México, mes de luna en el Ajusco y del clavel de sangre en el Guadarrama, inaugura su exposición con treinta cuadros [...] casi todos en escenas de ballet, que es no salirse de sí misma ni en el pincel del color, ni en la música de las alas. [...] Pero Maruja Bardasano, la aurora de Castilla en la Meseta de México, no es el padre ni es la madre. Es ella misma. De un barro semejante salen muy distintas molduras, por lo que Maruja Bardasano se ha moldeado a sí propia, cuajada de color, de gracia y de música. ${ }^{90}$

\section{El retorno a España y el valor de la pintura}

Los planes de Maruja de continuar su formación en Francia tuvieron un insalvable percance cuando, una vez comprados los billetes para viajar desde Nueva York — adonde llegaría en avión desde la ciudad de México-, el barco Andrea Doria, que iba a llevarla a Europa, se hundió el 25 de julio de 1956, ya próximo a arribar a la costa americana. Ésta fue la excusa perfecta de José Bardasano para convencer a su hija de que cambiara el destino a España, lo que además serviría para tantear de primera mano cómo estaba el panorama allí y, dado el caso, ir pensando en el retorno del resto de la familia. Así lo hizo Maruja, que conoció en el nuevo buque a Carlos Peña, quien se convertiría en su marido tres años después. Instalados en Madrid, la artista continuó por un tiempo su práctica de danza en la escuela de Karen Taft de la calle Libertad hasta el nacimiento de su primera hija, Carolina, a la que siguieron Rosalva y Beatriz. A pesar de su pasión por el ballet, la vida la llevó a quedarse solamente con la pintura.

Mientras tanto, en tierras mexicanas, José Bardasano sufrió un infarto en I957 que aceleró sus ganas de volver a su ciudad de origen, lo que consiguió definitivamente en 1960. El retorno de un artista tan significativo fue visto por muchos en España con recelo. A pesar de todo, protagonizó numerosas exposiciones y recibió reconocimientos, como la primera medalla del Salón de Otoño de 196r y la de honor de i966. En i964 fue condecorado con la medalla de oro de las Artes, Ciencias y Letras, y al año siguiente, con la Cruz de Oficial

90. Амв, "Exposición de dibujos de Maruja Bardasano", folleto, abril de 1955. 
al Mérito, así como con el premio del cartel turístico de Ginebra en 1967 a raíz de sus colaboraciones para Renfe. Por su parte, Juana Francisca Rubio también continuó acudiendo a eventos como el Salón de Otoño, en el que recibió una Segunda Medalla en 1961 y una Primera en 1964, aunque paulatinamente fue dejando los pinceles.

Asimismo, Maruja Bardasano protagonizó varias exposiciones individuales ya en España, fue la primera la de la Sala Díaz de la calle Los Madrazo número 6, inaugurada el i de marzo de $1966 .{ }^{91}$ Críticos como Jorge Campos apuntaron que sus dibujos, gouaches y acuarelas —en los que todavía aparecía el tema de la danza, como Coppélia, El cisne negro y Ballerina- estaban informados "de una gracia y de un maduro concepto que las hace sugestivas", 92 mientras que José Prados López, secretario perpetuo de la Asociación Nacional de Pintores y Escultores y crítico del diario Madrid, anotaba que la artista se presentaba "por vez primera en Madrid, segura de sí misma, consciente de su senda iluminada de verdades y bellezas [...] tiene abierta su ambición juvenil a las cuatro rosas de los vientos de la verdad". ${ }^{93}$ Para entonces ya había recibido varias distinciones: la medalla de oro del Círculo de Bellas Artes de México, la Cruz de Caballero al Mérito Nacional Francés, la medalla de plata de Artes, Letras y Ciencias de Francia y la Primera Medalla en el Salón de Otoño de $1964 .{ }^{94}$ En esos años, la artista comenzó a dar clases de pintura con gran éxito, actividad que continúa en la actualidad. ${ }^{95}$ En 1978 parte de sus alumnas junto a otros de L'Académie Européenne des Arts expusieron su obra en la madrileña Sala Cava Baja: Charo de Arpe, María Teresa del Campo, Carmen García Cabririzo, Piedad García Miranda, Malili García Oteiza, María Ester Garavilla (M.E.), Josefa Navarro, Conchita Ramirezony, Matuska de la Torre y María Pura Villar Palasí. ${ }^{96}$ Paralelamente, expuso en galerías y casas de subastas como las madrileñas Cano, Durán, Gavar, Segre, la valen-

9I. Амв, "Maruja Bardasano, cuarta pintora de la familia", recorte de prensa, in de marzo, s.a., Io; "Arte y artistas", $A B C, 2$ de marzo de 1966, 62.

92. A. M. Campoy, "Arte y artistas", $A B C$, 9 de marzo de I966, II.

93. АмB, José Prados López, "Maruja Bardasano", folleto de la "Exposición de dibujos de Maruja Bardasano", Sala de Arte Díaz, Madrid, marzo de 1960.

94. "XXXV Salón de Otoño", $A B C$, I de febrero de 1964, I3.

95. Entre otros lugares, una decena de sus discípulas expuso en la galería Cava Baja en junio de 1978. "Las exposiciones que se anuncian", $A B C$, il de junio de 1978, I03.

96. Амв, folleto de la exposición colectiva de la escuela Maruja Bardasano y de L'Académie Européenne des Arts; "Arte y artistas", $A B C, 29$ de junio de 1978, 33. 
ciana M. D. Segrelles del Pilar y las bilbaínas Bay-Sala y Juan Bayón, la Fundación Sotomayor - en una colectiva de la Asociación Española de Pintores y Escultores - (1984), La Torre de Guadarrama (1992) y la Sala de Arte P.E.A. Museo del Marco (2000). ${ }^{97}$

Sus referencias inmediatas en el mundo del arte, según la pintora, son Velázquez, Caravaggio, Zurbarán, Vermeer y Sorolla, entre otros, lo que marca muy bien las pautas perseguidas por su pintura. $9^{8}$ Ésta refleja, como apuntó Antonio Cobos, una belleza entendida como "el esplendor del orden, agustiniano, o al modo de la antigua Grecia, como idealización de las formas de la realidad viva". 99 En palabras de Luis Quesada, se descubre a una "excelente intérprete de la figura humana, tanto como retratista como en el cuadro de composición, usando a veces de una pincelada más jugosa y suelta que en el tratamiento de los bodegones, lo que evidencia un criterio ecléctico y disponibilidad de medios a la hora de encarar distintos asuntos”. De esta forma:

en la línea de la gran tradición española — continuaba el crítico—, que es tanto como decir universal, la construcción de los objetos se realiza en los cuadros de Maruja Bardasano con el hábil juego de la línea, de la mancha y del color [...]. La artista no se limita a copiar servilmente la realidad: la hace presente sobre la tela, crea una atmósfera que da vida a los objetos inanimados, poniendo de relieve la misteriosa entidad de las cosas que nos subyugan con su sola existencia. ${ }^{100}$

Los bodegones de Maruja Bardasano descubren la sutileza de los rincones cotidianos — Rincón de la cocina, La alacena, Rincón de mi casa- la atmósfera serena de las flores y frutas — Siemprevivas, Caléndulas, Manzanas y nueces, Lilas, Nisperos — , el brillo del cristal — Frascos, Frascas de tinto, Contraluz,

97. "Arte en Madrid", $A B C$, I9 de febrero de 1984, 9; "Noticias breves", $A B C$, I3 de abril de I980, IOI; Isabel Montejano, "Impulso cultural en el comienzo de la actual temporada veraniega", $A B C, 6$ de julio de 1992, 69; Isabel Montejano, "Exposición de la hija del pintor Bardasano en el centro 'La Torre', $A B C$, 19 de julio de 1992, 69; Maruja Bardasano, catálogo de la exposición (Madrid: Sala P.E.A., 2000).

98. Maruja Bardasano Rubio, "Conversación sobre su experiencia en el exilio del 39 con Idoia Murga", Seminario de Cultura Visual 2013-2014, Departamento de Historia del Arte y Patrimonio-Instituto de Historia/Consejo Superior de Investigaciones Científicas, Madrid, 2I de marzo de 2014.

99. Antonio Cobos, "El realismo riguroso y grácil de Maruja Bardasano", Maruja Bardasano, catálogo de la exposición (Bilbao: Galería Bay-Sala, 1992).

I00. Luis Quesada, Maruja Bardasano (Valencia: M. D. Segrelles del Pilar, 1992), 2. 


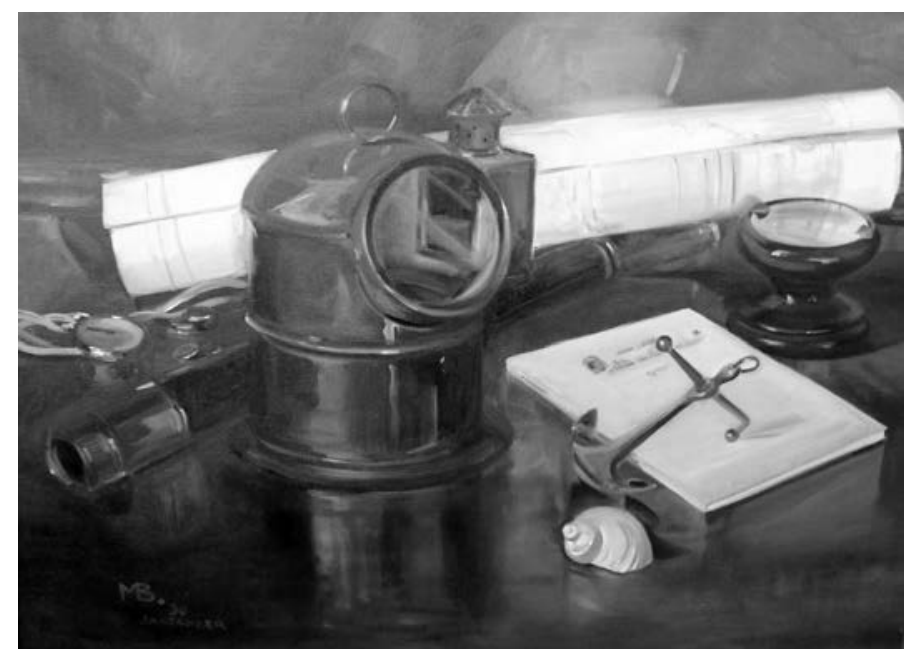

I3. Maruja Bardasano, Bodegón náutico, s.f., óleo sobre lienzo, $73 \times 100 \mathrm{~cm}$. Colección particular.

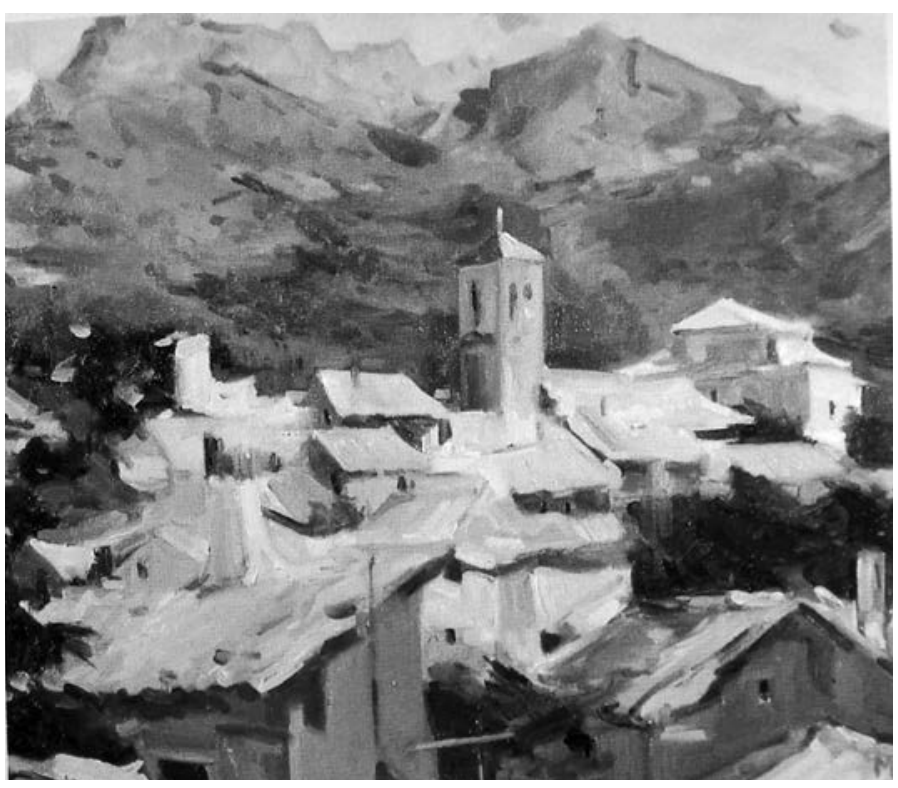

$\oplus$

I4. Maruja Bardasano, Cercedilla, s.f., óleo sobre lienzo, $50 \times 6 \mathrm{I} \mathrm{cm}$. Colección particular. 
Reflejo. Sus paisajes capturan instantes de luz de la sierra madrileńa, de la laguna de Venecia o de la fuerza del mar-Cercedilla, Bodegón náutico, Acqua alta en San Marcos, Venecia, Esperando al práctico, Acantilado (Homenaje a mi padre) (figs. I3 y I4).

La naturaleza sienta cátedra — apunta la pintora — y nos muestra su esplendor en explosión de formas, luces y colores, la más recóndita armonía, de la que tenemos obligación de tomar nota, del modelo como ejemplo. Por alguna razón se nos habrán puesto al alcance de la vista las pautas a seguir. Ser moderno no implica romper con las reglas. Todo gira en torno a las matemáticas. ${ }^{\text {IOI }}$

Los paisajes y las naturalezas muertas pintadas por la artista capturan los rincones ligados a sus experiencias y a su vida cotidiana, manteniendo siempre una coherencia en su manera de mirar al mundo.

Para Maruja Bardasano: "El artista nace, elegido por quien sea el que nos elige, al que en ese misterio llamamos Dios. El pintor se hace. Por eso el artista necesita del pintor para desarrollar su alma de artista. Yo nací para bailarina, pero necesité de la técnica para poder subir a un escenario a bailar Giselle" I02 Una técnica, a la que se refería en esta cita, que evidenciaba haber logrado una muy buena mano para el dibujo, presente siempre en la base de sus óleos. De esta forma, la madrileña deja clara su visión del trabajo y el esfuerzo en su búsqueda de la buena pintura:

Hoy por hoy parece haber una tendencia muy extendida a hacer las cosas de acuerdo con la ley del mínimo esfuerzo, o sea, a empezar la catedral por el campanario sin el sustento de los cimientos que la mantendrán en pie no obstante el riesgo de venirse abajo, ya que el derrumbe puede llegar a ser considerado por los "expertos aprovechados" como genialidad, que será aplaudida y galardonada, imponiendo al público cualquier mamarrachada, que el engañabobos encargado de lanzar el producto hará que el pretendido "genio" llegue a creerse que de verdad lo es y adopte, a sabiendas, la pose de tal genio ante el mundo, o siguiendo la corriente del fraude hará caer en la trampa de la especulación a tantos profanos sin criterio propio, fáciles de ser manipulados en su supina ignorancia por vía de la adulación y de la exageración del valor de la "ganga" adquirida. ${ }^{103}$

IOI. Bardasano Rubio, "Conversación sobre su experiencia en el exilio".

IO2. Bardasano Rubio, "Conversación sobre su experiencia en el exilio".

I03. Bardasano Rubio, "Conversación sobre su experiencia en el exilio". 
A la espera de ser objeto de un estudio pormenorizado desde sus primeras obras de juventud en México hasta los cuadros que sigue iluminando en la actualidad, la pintura de Maruja Bardasano permanece fiel a su manera de entender el arte y el oficio, ajena a los vaivenes de modas y tendencias del mercado, dando continuidad a la saga de su creativa familia.

\section{Conclusiones}

A la luz de los focos escénicos y del color de los pinceles, Maruja Bardasano ha desarrollado una interesante trayectoria artística, marcada por el particular contexto del exilio republicano español en México tras la guerra civil. Sin duda fue su faceta como bailarina la que desarrolló con más intensidad durante su juventud en el exilio, una trayectoria todavía poco conocida en la historia de la danza mexicana, a pesar de que tuvo lugar en el periodo de brillante despegue nacional de estas disciplinas. En esos años compartió escenario con indiscutibles personalidades del ballet mexicano y llegó a ser primera solista de su compañía. A pesar de que el desarrollo más innovador en el campo de la danza mexicana llegó de la mano de la técnica moderna y de que, en líneas generales, los bailarines exiliados españoles practicaron el flamenco, el folclor ibérico, la danza estilizada española o la escuela bolera, la de Maruja Bardasano fue una preferencia clara por el ballet clásico, lo que la convierte en una excepción en su campo. Aunque hasta el momento no he localizado filmaciones de las actuaciones de esta bailarina, las fotografías conservadas permiten apreciar una correcta técnica de influencia rusa que sin duda combinó con esa gran expresividad a la que se refirieron los críticos del momento.

Asimismo, su sólida formación como pintora y sus preferencias en el lenguaje pictórico deben entenderse siempre ligadas a la rotunda presencia y actividad familiar, sobresaliente ya desde los ańos de la Segunda República Española y continuada gracias a la acogida de los refugiados por el gobierno de Cárdenas. Con todo, al día de hoy la obra pictórica de Maruja Bardasano se encuentra dispersa y es especialmente dificultoso el acceso a su producción de juventud, por lo que queda pendiente un estudio exhaustivo de su labor como pintora, que trasciende los objetivos de esta investigación. Sin duda en aquellos ańos la artista estaba más centrada en la danza, mientras que - a pesar de que su doble dedicación artística llamó en muchas ocasiones la atención de la prensa- su pintura no cobró relevancia hasta prácticamente su exposición 
en el Círculo de Bellas Artes mexicano, poco antes de su retorno a España. La incuestionable exigencia que requiere el ballet clásico en términos de dedicación, horas de ensayo, esfuerzo físico y disciplina probablemente condicionó tal preferencia en los ańos de su juventud en detrimento de su pintura. Por el contrario, ya establecida en España, aunque por un tiempo limitado tomó clases en la pionera escuela de danza de la capital, Maruja Bardasano acabó volcándose en sus cuadros. Con el paso del tiempo, aquellas bailarinas que había pintado en los años cincuenta acabaron dando paso a una temática alejada de los escenarios, centrada ya en bodegones, retratos y paisajes, enfrentada a una nueva etapa vital y profesional.

Si bien sus circunstancias personales y familiares en su condición de exiliada no se reflejaron ni en las coreografías que interpretó ni en los temas de sus pinturas, ajenas, a diferencia de las producciones de otros artistas — incluyendo sus progenitores-, a la propaganda, al compromiso político, a la denuncia de la causa republicana y de las consecuencias de la guerra y a los desplazamientos forzosos, quizá sí se puede entender la influencia de este particular contexto histórico y cultural en su elección de lenguaje, claramente situado en el realismo. El gusto por el repertorio clásico de los grandes ballets y el academicismo de su formación técnica dancística tienen un paralelismo en el vocabulario plástico reflejado en su pintura, marcado sin duda por el realismo que siempre cultivaron sus padres y que podría entenderse como secuela indirecta de los debates estéticos de aquellos convulsos años treinta en España y su posterior establecimiento en México.

Con todo, la importancia del círculo familiar de la bailarina no sólo se reflejó en sus preferencias plásticas, sino que, como se ha podido comprobar, cierta parte de la historia de las compañías de las que fue miembro Maruja estuvo condicionada por la presencia de los Bardasano-Rubio en México. Así se explica, por ejemplo, que la fiesta de despedida de Nelsy Dambre tuviese lugar en la casa familiar o que varios espectáculos del Ballet Concierto se organizaran en el Círculo de Bellas Artes, fundado por el padre de la artista. Fue precisamente José Bardasano quien dibujó el retrato de Sergio Unger con el que ilustró gran parte de los programas de mano de la compañía que circularon por México, y tanto él como Juana Francisca se relacionaron con los coreógrafos e intérpretes compañeros de su hija e intervinieron de manera puntual aconsejándoles sobre puestas en escena o figurinismo.

En definitiva, Maruja Bardasano es una artista de sólida personalidad, en quien apreciamos la cristalina sinceridad en la defensa de su manera de 
entender la pintura y la experiencia de quien ha pasado años formándose en la disciplina del ballet y en el dominio de los pinceles. Horas de ensayos, de repeticiones de unos mismos movimientos, de control técnico del cuerpo e interpretación de personajes, emociones y músicas. Bocetos y dibujos de unos mismos motivos, hasta alcanzar la soltura técnica de quien ha educado el ojo desde la cuna. Su obra es sin duda el producto de una vida marcada por el esfuerzo y la constancia, el trabajo bien hecho, la formación integral en las artes, la convivencia de la cultura espańola y la mexicana y el amor por la belleza clásica. \$

N.B. Este texto se realizó en el marco de los proyectos de investigación Plan Nacional de I+D+i, Tras la República: redes y caminos de ida y vuelta en el arte espańol desde 193I (ref: HAR20II-25864) y 50 ańos de arte en el Siglo de Plata espańol (I93I-I98I) (ref: HAR2or45387i-P), así como el Seminario Complutense: Historia, Cultura y Memoria. 